\title{
Catalytic Radical Domino Reactions in Organic Synthesis
}

\author{
Leanne J. Sebren, James J. Devery III, and Corey R.J. Stephenson ${ }^{*}$ \\ Department of Chemistry, University of Michigan, Ann Arbor, MI
}

\begin{abstract}
Catalytic radical-based domino reactions represent important advances in synthetic organic chemistry. Their development benefits synthesis by providing atom- and step-economical methods to complex molecules. Intricate combinations of radical, cationic, anionic, oxidative/reductive, and transition metal mechanistic steps result in cyclizations, additions, fragmentations, ringexpansions, and rearrangements. This Perspective summarizes recent developments in the field of catalytic domino processes.
\end{abstract}

\section{Keywords}

radical; domino; cascade; tandem; transition metal; photoredox

\section{Introduction}

Synthetic organic chemists continuously pursue new reactions and chemoselective transformations under mild conditions. To this end, new methods for the facile and efficient installation of complexity in small molecules are in constant development. The ideal transformation is an efficient single reaction with one set of reagents that yields a desired product. Great efforts have been made to develop efficient single step transformations, which result in the formation and fragmentation of multiple bonds in a step-wise fashion. These reactions have been termed domino, cascade, or tandem processes. ${ }^{1}$

A domino reaction is a transformation that installs two or more bonds under identical conditions. The advantages of methods that construct complex molecules in a single reaction are self-evident, providing both atom ${ }^{2}$ and step economy. ${ }^{3}$ Tietze has described at length the factors that define a domino reaction. ${ }^{1 \mathrm{f}}$ First, all reactants and reagents must be added at the beginning of the process without further addition. Next, two or more bonds must be formed or, in some cases, broken. Each bond-forming step must happen sequentially, resulting in a "time-resolved succession of steps" that occur linearly from the point of view of a reaction mechanism. ${ }^{1 \mathrm{~b}}$ The steps within the mechanism can be classified as cationic, anionic, pericyclic, photochemical, transition-metal mediated, oxidative or reductive, enzymatic, or radical.

Historically, organic radicals were deemed uncontrollable and unselective except under tightly managed reaction conditions. However, great mechanistic efforts have been applied to gain insight into the reactivity of the free radical in order to understand how best to apply this reactive intermediate. As a result, radical-mediated processes provide nonpolar access to the formation of carbon-carbon and carbon-heteroatom bonds. ${ }^{4}$ Traditional radical domino reactions are thought of as a series of rapid intramolecular cyclizations of pendant olefins

‘Corresponding Author. crjsteph@umich.edu.

The authors declare no competing financial interest. 
and alkynes. However, radical-based domino processes have emerged that undergo additions, fragmentations, ring-expansions, and rearrangements under a variety of conditions.

Many radical transformations that proceed through atom transfer are initiated by the addition of stoichiometric stannanes, silanes, or peroxides. Additionally, these reactions typically require the use of, albeit a substoichiometric amount, an unstable initiator. ${ }^{5}$ Redox-mediated transformations usually require one or more equivalents of metal oxidant or reductant. ${ }^{6}$ Both of these methods are routinely utilized in organic synthesis; however, radical transformations that utilize a catalytic electron transfer agent alleviate the need for stoichiometric metals or harsh atom abstractors. Significant efforts have been focused towards the development of catalytic radical reactions using redox-active transition metals ${ }^{7}$ and photo-active catalysts. ${ }^{8}$

This Perspective outlines recent efforts to apply catalytic electron transfer agents towards the development of radical domino reactions. The selection of transformations within highlights the diverse number of methods available to synthetic chemists. Many examples of catalytic radical-mediated processes exist, but we seek to display those that form/break two or more bonds prior to the generation of the final product. These examples were chosen because a radical participates in at least the first bond-forming step and that one or more subsequent steps result from this initial transformation.

\section{Transition metal-mediated domino reactions}

The seminal works of Kharash, ${ }^{9}$ Kochi, ${ }^{10}$ and Minisci ${ }^{11}$ clearly demonstrated that carbon radicals could be formed in the presence of a transition metal catalyst. Since their efforts, a great number of transformations have been reported in the literature., ${ }^{72}$ These methods employ copper, manganese, iron, cobalt, titanium, and ruthenium catalysts to perform atom transfer, as well as single electron reductions and oxidations. In recent years, radical domino reactions utilizing transition metal complexes have garnered considerable attention. These systems combine traditional radical transformations with cationic, anionic, oxidative, reductive, or pericyclic steps to provide access to fragmentations, rearrangements, and complex ring systems.

$\mathrm{Cu}$-mediated atom transfer radical cyclizations (ATRC) have been developed extensively over the years. ${ }^{7}$ In 2007, Quayle and coworkers continued their development of $\mathrm{Cu}$ mediated ATRC reactions with trichloroacetates. ${ }^{13}$ They observed that microwave irradiation at $200{ }^{\circ} \mathrm{C}$ supplemented the ATRC reaction of $\mathbf{1}$, resulting in a domino benzannulation to form chloronaphthalenes (Figure 1). The authors propose a radical/ radical/pericyclic/anionic domino process. Beginning with a $\mathrm{Cu}(\mathrm{I})$-mediated chlorine atom transfer from 11, dichlororadical $\mathbf{4}$ and $\mathrm{Cu}$ (II) complex 5 are formed at the onset. Radical 4 then undergoes a preferred 8-endo-trig cyclization ${ }^{14}$ to yield radical $\mathbf{6}$, which is then chlorinated by 5 to form lactone 7. Quayle et al. detected no annulation when 7, easily accessible via conventional heating, was irradiated for $2 \mathrm{~h}$ in the absence of other reagents. 2 was only observed in the presence of $\mathrm{CuCl}$ and $\mathbf{3}$. As a result, they proposed that 7 reacts with a second $\mathrm{Cu}$ complex to yield radical 8 and chloro-complex 5 . This radical then undergoes a reversible 4-exo-trig cyclization, which is facilitated by chlorine atom transfer from 5, to form spirolactone 9. Retro [2+2] cyclization, driven by elimination of $\mathrm{CO}_{2}$, converts 9 to $\mathbf{1 0}$, which, upon the elimination of 2 equiv $\mathrm{HCl}$, yields 4-chlorophenanthrene (2).

In 2006, Yang et al. found that ATRC reactions of $\alpha, \alpha$ '-dichloro- $\beta$-ketoesters could be facilitated by $30 \mathrm{~mol} \% \mathrm{CuCl}$ in the presence of chiral, bidentate amine ligands (Figure 2). ${ }^{15}$ 
However, when the system was extended beyond the formation of a single C-C bond, use of 2,2'-bipyridine (bpy) provided optimal reactivity. The domino bicyclization occurs through a radical/radical process initiated by removal of a chlorine atom from $\mathbf{1 1}$ by $\mathrm{Cu}(\mathrm{I})$. Radical 13 then undergoes a 6-endo-trig cyclization to form 14, which is then trapped by a rapid 5exo-trig cyclization to yield primary radical 15 . The primary radical then reacts with $\mathrm{Cu}$ (II) complex $\mathbf{1 4}$ to form $\mathbf{1 2}$ in a $61 \%$ yield as a 2.3:1 ratio of diastereomers and turnover of the catalyst.

Pérez, Belderraín, and Muñoz-Molina developed a diastereoselective Cu-catalyzed ATRC domino reaction (Figure 3). ${ }^{16}$ Additionally, they found that when $\mathrm{Mg}$ was added as a reducing agent, they observed improved yields. This radical/radical process is initiated by abstraction of a chlorine atom from $\mathrm{CCl}_{4}$. The resulting trichloromethyl radical then adds to one of the allyl groups of $\mathbf{1 7}$ to form radical 19. This product radical then undergoes a rapid 5-exo-trig cyclization followed by chlorine atom transfer to provide $\mathbf{1 8}$ in a $99 \%$ yield and turn over the catalyst. Pintauer and coworkers found that the turnover efficiency of this $\mathrm{Cu}$ mediated reaction could be greatly enhanced to where only $0.01 \mathrm{~mol} \%$ catalyst is required with tris(2-pyridylmethyl)amine as a ligand and substoichiometric amounts of either a diazo initiator ${ }^{17}$ or ascorbic acid ${ }^{18}$ as reducing agents.

In their seminal work, Mori and Ban first demonstrated the ability of low-valent Pd to mediate ATRC processes of a-haloamides. ${ }^{19}$ In recent years, chemists have catalytic single electron reductions with carbonylations. Ryu, Komatsu, and coworkers found that when $\mathbf{2 1}$ was exposed to light under 40 atm of $\mathrm{CO}$ and a catalytic amount of $\mathrm{Pd}\left(\mathrm{PPh}_{3}\right)_{4}, \gamma$-ketoester 22 was formed (Figure 4). ${ }^{20}$ They propose a radical/radical/radical/reduction process. Under irradiation, an iodine atom is removed from $\mathbf{2 1}$ by $\mathrm{Pd}(0)$ to form primary radical $\mathbf{2 3}$. This radical adds to $\mathrm{CO}$, forming $\mathbf{2 4}$, and then undergoes a rapid 5-exo-trig cyclization, yielding radical 25 . The resulting $\beta$-keto radical then attacks another equivalent of $\mathrm{CO}$ to form 26, which is reduced by $\mathrm{Pd}(\mathrm{I})$ to form organopalladium(II) complex 27. Addition of butanol and reductive elimination yields 22 and turns over the catalyst. They later found that when $\mathrm{H}_{2} \mathrm{O}$ and a boronic acid (28) were substituted for the alcohol, transmetallation and reductive elimination resulted in the formation of diketone $\mathbf{2 9}$ (Figure 5). ${ }^{21}$

Continuing their work on radical carbonylations, Ryu and coworkers designed a method for the formation of lactones (32) from their conditions (Figure 6). ${ }^{22}$ When irradiated with light, this radical/radical/reduction process begins with the abstraction of an iodine atom from $\mathbf{3 0}$ to form radical 33. This primary radical then adds to olefin $\mathbf{3 1}$ to form $\mathbf{3 4}$, which can add to an equivalent of $\mathrm{CO}$ to form keto-radical 35. Reduction of this intermediate results in the formation of organopalladium(II) complex 36. Addition of the pendant hydroxyl group and reductive elimination regenerates the catalyst and forms lactone $\mathbf{3 2}$ in a $77 \%$ yield.

Similarly, Alexanian and Bloom found that an analogous transformation could be mediated by low-valent palladium in the absence of light. ${ }^{23}$ Alkyl iodide $\mathbf{3 7}$ participates in a carbonylative-Heck reaction at elevated temperatures in toluene to give spirocyclopentanone 38 (Figure 7). This radical/radical/oxidative process begins with removal of an iodine atom from $\mathbf{3 7}$ to form primary radical 39. Similar to the mechanism in Figure 4, radical addition to $\mathrm{CO}$ provides access to a rapid 5-exo-trig cyclization, yielding tertiary radical 41. Single electron oxidation by $\mathrm{Pd}(\mathrm{I})$ yields tertiary cation $\mathbf{4 2}$, which can undergo facile deprotonation at the newly formed a-position of $\mathbf{3 8}$.

Oshima and coworkers developed a Co-mediated process that is initiated by atom transfer in 2003. ${ }^{24}$ They observed that when $\mathbf{4 3}$ and $\mathbf{4 4}$ were combined in the presence of trimethylsilylmethylmagnesium chloride and a catalytic amount of $\mathrm{CoCl}_{2}$ ligated by 1,6bis(diphenylphosphino)hexane (dpph), silane $\mathbf{4 5}$ was produced in excellent yield (Figure 8). 
This transformation provides insight into the mechanism. Furan $\mathbf{4 8}$ was produced via a radical/radical/reduction/Tsuji-Trost allylation process. A bromine atom is removed from 43 by $\mathrm{Co}(0)$ to form primary radical 46 and $\mathrm{Co}(\mathrm{I})$ complex 47 . This primary radical undergoes rapid 5-exo-trig cyclization to form $\mathbf{4 8}$, which then adds to butadiene 44 . Allylic radical 49 is then reduced by $\mathbf{4 7}$ to form complex $\mathbf{5 0}$. The metal center of $\mathbf{5 0}$ is then alkylated by the Grignard reagent to form $\mathbf{5 1}$, which undergoes reductive elimination to form furan $\mathbf{4 5}$ and regenerate the catalyst.

$\mathrm{Fu}$ and Cardenas independently developed Ni-catalyzed cross-coupling methods initiated by atom transfer. Initially, Fu et al. demonstrated that both Ni-catalyzed Stille cross-couplings 25 and Suzuki cross-couplings ${ }^{26}$ of secondary alkyl halides began via low-valent Ni-mediated radical formation (Figure 9). Later, Cardenas et al. demonstrated the same radical process for Ni-catalyzed Negishi cross-coupling of secondary alkyl halides. ${ }^{27}$ These three methods proceed through similar radical/reduction/anionic domino sequences. Initially, a halogen atom is removed from alkyl halide $\mathbf{5 9}$ to form secondary radical $\mathbf{6 0}$ and $\mathrm{Ni}(\mathrm{I})$ complex $\mathbf{6 1}$. The secondary radical undergoes rapid 5-exo-trig cyclization to form primary radical 62, which is then reduced by $\mathbf{6 1}$ to form organonickel $\mathbf{6 3}$. This complex undergoes transmetallation with agent 64 to form organonickel 65 . Upon reductive elimination, $\mathrm{Ni}(0)$ is regenerated, yielding $\mathbf{6 6}$.

In addition to atom transfer reactions, radical-mediated domino reactions can be initiated with single electron reductions. In 2012, Barrero, Moral, and coworkers applied a radical/ radical/oxidation domino process to the total synthesis of (+)-seco-C-oleanane $(\mathbf{6 8 A})$ (Figure 10). ${ }^{28}$ Most notable about this synthesis is that performing this reaction with a substoichiometric amount of $\mathrm{Cp}_{2} \mathrm{TiCl}_{2}$ improved the efficiency of the desired 6-endo-trig/6endo-trig bicyclization process over the use of stoichiometric Ti reductant. The authors propose that this process begins with single electron reduction and ring-opening of epoxide 67 to give tertiary radical 69. This radical then undergoes two consecutive 6-endo-trig radical cyclizations to form radical 71. Hydrogen atom abstraction of hydrogen atoms A or B (Figure 10) followed by TMS-protection yields TMS protected TMS-68A as well as TMS protected $\beta$-seco-amyrin (TMS-68B).

Similar to the reductive capabilities of Ti(III), Aubé et al. utilized the reducing power of $\mathrm{Cu}(\mathrm{I})$ to ring-open chiral oxaziridines to form nitrogen-centered radicals (Figure 11). ${ }^{29}$ They observed that when oxaziridine $\mathbf{7 2}$ was refluxed in THF in the presence of $\left[\mathrm{Cu}\left(\mathrm{PPh}_{3}\right) \mathrm{Cl}\right]_{4}$, pyrroline $\mathbf{7 3}$ was formed in 66\% yield with greater than $95 \%$ ee. This radical rearrangement potentially occurs through a radical/radical/oxidation/pericyclic domino process. At the onset, $\mathrm{Cu}(\mathrm{I})$ reduces oxaziridine $\mathbf{7 2}$, which ring-opens to form nitrogen-centered radical $\mathbf{7 4 .}$ Rapid 5-exo-trig cyclization of $\mathbf{7 4}$ results in pyrrolidine radical $\mathbf{7 5}$. The authors then propose that radical $\mathbf{7 6}$ is formed when $\mathbf{7 5}$ undergoes 1,4-aryl migration via ipso attack on the aryl ring. Finally, $\mathrm{Cu}(\mathrm{I})$ and acetaldehyde are eliminated to form pyrroline $\mathbf{7 3}$. While not proposed by the authors, this rearrangement/elimination may be initiated by single electron oxidation of the alkoxide to form an oxygen-centered radical and regenerate the catalyst. Intramolecular radical coupling results in the formation of $\mathbf{7 7}$, which can undergo a retro $[2+2]$ cyclization to form pyrroline $\mathbf{7 3}$.

Conversely, when the oxaziridine diastereomer $\mathbf{7 8}$ was exposed to the same conditions, a radical/radical domino process is observed that results in rearrangement to aziridine $\mathbf{7 9}$ (Figure 12), initiated by a Cu-mediated ring-opening of 78. An analogous 5-exo-trig cyclization of $\mathbf{8 0}$ leads to pyrroline radical $\mathbf{8 1}$. However, they propose that the transition state that would result in phenyl transfer is disfavored due to the steric constraints of this diastereomer. As a result, intramolecular radical addition to the nitrogen simultaneously 
forms an aziridine moiety and ring-opens the pyrrolidine, resulting in benzylic radical $\mathbf{8 2}$. Single electron oxidation by $\mathrm{Cu}(\mathrm{II})$ regenerates the catalyst and yields $\mathbf{7 9}$.

$\operatorname{Ag}(\mathrm{II})$ is a powerful oxidant that is easily generated by the combination of $\operatorname{Ag}(\mathrm{I})$ and persulfate, which has been utilized by chemists for decades. ${ }^{30} \mathrm{~A}$ considerable wealth of mechanistic and kinetic information has been compiled over the years, and chemists use these data to develop new transformations. In 2006, Narasaka and coworkers applied this oxidative system to the single electron-mediated ring-opening of cyclopropanols (Figure 13). ${ }^{31}$ Notably, this method provided diminished yields when performed in the absence of pyridine. The improvement is attributed to coordination of pyridine to $\mathrm{Ag}(\mathrm{I})$, activating the metal towards oxidation by persulfate. ${ }^{32}$ Attachment of a pendant olefin to the cyclopropanol provided access to $\mathbf{8 4}$. This reaction occurs via a radical/radical domino process. $\mathrm{Ag}$ complex 85 is oxidized by persulfate to $\mathrm{Ag}$ (II) complex 86, which is capable of oxidizing cyclopropanol $\mathbf{8 3}$ to an alkoxy radical. This radical then undergoes a retro 3-exotrig cyclization to form heptanone radical 88. A 5-exo-trig cyclization forms primary radical $\mathbf{8 9}$, which abstracts a hydrogen atom from 1,4-cyclohexadiene to form $\mathbf{8 4}$.

Yao, Hu, Zhang, and coworkers utilized the Minisci reaction ${ }^{33}$ to generate fused pentacycles (92) from indolylpropanoic acids (90) and quinones (91) (Figure 14). ${ }^{34}$ These carbazoles are formed via a radical/radical/radical/oxidation/anionic/oxidation domino process. This transformation begins by oxidation of $\mathrm{Ag}(\mathrm{I})$ to $\mathrm{Ag}(\mathrm{II})$, which then oxidizes $\mathbf{9 0}$ to a carboxy radical (93). Elimination of $\mathrm{CO}_{2}$ leads to primary radical 94 that adds to quinone 91 . Radical 95 then undergoes a 6-endo-trig cyclization with the pendant indole to complete the pentacyclic framework. Next, tertiary radical 96 is converted to 97 via one of three pathways: 1) hydrogen atom abstraction, 2) oxidation to the cation and then deprotonation, 3 ) deprotonation to the radical anion followed by oxidation. The central ring of the pentacycle is then aromatized via elimination of $\mathrm{HBr}$ and oxidation to yield $\mathbf{9 2}$.

In 2010, Baran and coworkers developed an intermolecular Minisci reaction for boronic acids. ${ }^{35}$ A year later, they demonstrated an intramolecular variant that could utilize either boronic acids or trifluoroborates (Figure 15). ${ }^{36}$ Utilizing quinones as radicophiles, the Baran group were able to perform a radical/radical domino reaction to yield $\mathbf{1 0 0}$. In this process, $\mathrm{Ag}$ (II) is generated via a persulfate-mediated single electron oxidation. Then, $\mathrm{Ag}$ (II) oxidizes quaternized $98^{37}$ to form aryl radical 101, which cyclizes to secondary radical 102 . Quinone $\mathbf{9 9}$ then adds to the radical and forms $\mathbf{1 0 0}$ after hydrogen atom abstraction.

MacMillan et al. devised a series of domino reactions by combining the properties of the SOMO-activated addition of styrene ${ }^{38}$ and the intramolecular arylation. ${ }^{39}$ In the original styrene approach, the product was formed by internal ligand transfer of a nitrate from ceric ammonium nitrate to a benzylic cation. MacMillan and coworkers utilized this electrophilic intermediate for follow-up nucleophilic attacks from aromatic ring and pendant, protected amines. ${ }^{40}$ Application of these nucleophiles provides access to multicyclic ring systems containing substituted benzenes such as $\mathbf{1 0 5}$ (Figure 16) or pyrrolidines. These cyclizations proceed through a radical/oxidation/cationic domino mechanism. First, condensation of aldehyde 103 and catalyst 106 forms electron-rich enamine 107, which is then oxidized by $\mathrm{Fe}$ (III) to yield radical cation 108. Addition of radicophile 104 to 108 yields product radical cation 109. A secondary Fe(III)-mediated oxidation forms dication 110, which then undergoes an intramolecular Friedel-Crafts alkylation, proton transfer, and hydrolysis to form $\mathbf{1 0 5}$ and regenerate the catalyst.

The MacMillan group further extended the reactivity of the radical intermediate through unsaturations in polyenes to form multiple fused six-membered rings in one reaction with high enantioselectivity (Figure 17). ${ }^{41}$ Reaction of $\mathbf{1 1 3}$ in the presence of catalyst $\mathbf{1 1 5}$ and 
$\mathrm{Cu}$ (II) as an oxidant formed hexacyclic $\mathbf{1 1 4}$ in $63 \%$ yield and 93\% ee. This domino reaction undergoes four consecutive 6-endo-trig cyclizations. The mechanism is initiated by condensation of $\mathbf{1 1 3}$ with $\mathbf{1 1 5}$ to form an enamine, which is oxidized by $\mathrm{Cu}$ (II) to form distonic radical cation 116. This radical cation then undergoes rapid and successive 6-endotrig cyclization, terminating in the formation of conjugated radical 117. Oxidation and elimination of a proton yield iminium 118, which, upon hydrolysis, releases catalyst $\mathbf{1 1 5}$ and forms 114.

\section{Domino reactions mediated by photoredox catalysis}

Visible light photoredox catalysis has established itself as a powerful technique for enacting free radical transformations. ${ }^{8,42}$ Typical photocatalysts are transition metal complexes or organic dyes that, upon photoexcitation by visible light to an excited triplet state, can proceed through oxidative or reductive quenching pathways to enact single electron transfers (Figure 18). It is emerging as a versatile and advantageous technique for mediating free radical reactions for several reasons. First, photoredox catalysts are activated by visible light, and unlike a traditional photochemical apparatus, reactions are conducted in typical borosilicate glassware with simple light fixtures. Second, the stoichiometric electron carrier is typically an inexpensive amine as opposed to stannanes or silanes found in traditional radical processes. Finally, reactions are very robust with typical transformations proceeding efficiently at low catalyst loadings.

In 2013, Zhu and coworkers developed a visible light-mediated, room temperature, decarboxylation/aromatic substitution of aniline $\mathbf{1 1 9}$ to oxindole $\mathbf{1 2 0}$ (Figure 19) via a radical/radical/cation domino process. ${ }^{43}$ In this transformation, the excited state of $\operatorname{Ir}(\mathrm{ppy})_{3}$ is oxidatively quenched by iodosobenzene diacetate (PIDA). The PIDA radical then fragments into iodobenzene, $\mathrm{CO}_{2}$ and a methyl radical, which adds to 119. Intramolecular cyclization to the arene installs the quaternary center in $\mathbf{1 2 2}$. Thereafter, oxidation to the resonance stabilized cation followed by deprotonation leads to aromatization of the 3disubstituted product.

In 2012, König and coworkers developed an eosin Y-catalyzed synthesis of benzothiophene derivatives (126) (Figure 20). ${ }^{44}$ This method utilizes a radical/radical/oxidative/cation domino reaction to access these heteroarenes. Starting from the $o$-methylthiobenzenediazonium salt 124, visible light irradiation excites the photocatalyst to the triplet state, which is oxidatively quenched by the diazonium salt to release $\mathrm{N}_{2}$ gas and aryl radical 127. In the presence of $p$-nitro phenyl acetylene (125), radical addition yields vinyl in the radical 128. Addition to sulfur followed by oxidation forms thionium 130. Methyl transfer results in formation of $\mathbf{1 2 6}$.

In a recent report by Zhou and coworkers, eosin Y induced a [4+2] benzannulation of biaryldiazonium salts with alkynes (Figure 21). ${ }^{45}$ This radical/radical/cation domino reaction produced a variety of 9- and 9,10-disubstituted phenanthrenes. Irradiation with visible light excites eosin Y from the ground state. A single electron transfer from the excited photocatalyst to aryl diazonium $\mathbf{1 3 1}$ results in the radical cation of the catalyst and aryl radical 134. Radical addition to alkyne 132 affords vinyl radical 135. Intramolecular cyclization followed by single electron oxidation yields the carbocation 137 and the regenerated catalyst. Finally, deprotonation of $\mathbf{1 3 7}$ results in desired phenanthrene $\mathbf{1 3 3}$.

The Stephenson group reported a tin-free reductive dehalogenation reaction utilizing a visible light activated photocatalyst in $2009 .{ }^{46}$ This method, which formed a radical intermediate, was applied to the functionalization of indoles and pyrroles (Figure 22) ${ }^{47}$ Utilizing the radical generated from $\mathrm{C}-\mathrm{Br}$ cleavage, a radical/radical/oxidation process 
yielded tetracyclic indole 139. The proposed mechanism begins with irradiation of the photocatalyst with visible light to afford an electron accepting excited state that is reductively quenched by triethylamine to form a triethylamine radical cation and $\mathrm{Ru}(\mathrm{I})$. Reduction of the C-Br bond of $\mathbf{1 3 8}$ affords tertiary radical $\mathbf{1 4 0}$, which undergoes successive 5-exo-trig and 6-exo-trig cyclizations to form radical 142. The indole radical is then rearomatized, affording the tetracyclic product $\mathbf{1 3 9}$.

Inspired by the work of Curran ${ }^{48}$ and Tanabe, ${ }^{49}$ Stephenson and coworkers continued to develop radical/radical domino reactions onto unactivated $\pi$-systems. ${ }^{50}$ The reaction led to a variety of products including 5- and 6-membered rings as well as fused and spiro products (Figure 23). When applied to this domino system, photoexcitation of the metal catalyst and reductive quenching affords the active single electron reductant $\mathrm{Ru}(\mathrm{I})$. The electron rich catalyst then reduces the $\mathrm{C}-\mathrm{Br}$ bond of $\mathbf{1 4 4}$ to yield the regenerated $\mathrm{Ru}(\mathrm{II})$ and radical $\mathbf{1 4 6}$. This radical then undergoes two successive 5-exo-trig cyclizations to form vinyl radical 148. Finally, the carbon radical abstracts a hydrogen atom to form tricyclic product $\mathbf{1 4 5}$ in a $69 \%$ yield.

Following the development of a general cyclization strategy, the Stephenson group applied this concept to the formation of tricyclic pyrrolidinones (Figure 24). ${ }^{51}$ The system proceeds through either a radical/radical/pericyclic or a radical/radical/radical domino mechanism. The reaction, outlined in Figure 24, begins with the reductive quenching of photoexcited $\mathrm{Ir}(\mathrm{III})$ by $\mathrm{Et}_{3} \mathrm{~N}$ to form an $\mathrm{Ir}(\mathrm{II})$ complex. Single electron transfer to 149 provides a-radical 151, which quickly undergoes a 5-exo-dig cyclization with the pendant alkyne to form lactam 152. At this point, the mechanism was less clear. In path A, 152 can undergo hydrogen atom abstraction followed by a thermal sigmatropic rearrangement that is driven by strain release of the cyclopropyl ring to yield $\mathbf{1 5 0}$. Alternatively, radical $\mathbf{1 5 2}$ can undergo an additional cyclization onto the aromatic ring, followed by $\beta$-scission to form radical 154B (path B). Then, isomerization and hydrogen atom abstraction may lead to product $\mathbf{1 5 0}$. Interestingly, trace quantities of $\mathbf{1 5 3 A}$ were isolated from the reaction mixture. To provide further mechanistic insight, intermediate $153 \mathrm{~A}$ was heated at $40{ }^{\circ} \mathrm{C}$ in DMF in the absence of other redox conditions. The desired fused pyrrolidinone (150) was the only observed product, suggesting that path $\mathbf{A}$ is the likely route.

In 2008, the Yoon group developed a photocatalytic [2+2] reductive cyclization of a (bis)enone bearing a three-carbon tether. ${ }^{52}$ Later, the authors observed that when the bis(enone) tether was expanded by the addition of a methylene unit under the same conditions, the expected products were not formed and the observed products included dihydropyran 157 (Figure 25). ${ }^{53}$ Intrigued by this observation, the authors optimized a photocatalytic radical/radical reaction to access dihydropyrans. The proposed mechanism involves reductive quenching of the excited state of the ruthenium catalyst, followed by single electron reduction of Li-activated (bis)enone (LA-156) to form radical 158. This allylic radical then undergoes a 6-exo-trig cyclization to form a-radical 159. Enolate attack on the a-radical leads to ketyl $\mathbf{1 6 0}$, which is then oxidized to form desired tetrahydropyran $\mathbf{1 5 7}$ in high yield (86\%).

Continuing their efforts to combine Lewis acid activation with photoredox catalysis, the Yoon group reported a photocatalytic [3+2] cycloaddition of activated cyclopropanes with olefins (Figure 26) ${ }^{54}$ This radical/radical/radical domino process results in the formation of fused cyclopentane rings. Single electron reduction of LA-activated 161 by the photocatalyst results in ketyl radical anion formation (163). The subsequent retro 3-exo-trig cyclization drives the reaction forward to allyl radical 164. Facile 5-exo-trig cyclization onto the pendant olefin forms tertiary radical intermediate 165. Finally, ring closure via another 
5-exo-trig cyclization and single electron oxidation affords fused [3.3.0] product 162 in a 6:1 diastereomeric ratio.

In 2012, Zhao and coworkers showcased a visible light-initiated reductive coupling/aldol cyclization of chalcones (Figure 27) ${ }^{55}$ During preliminary studies, the expected $[2+2]$ cyclobutane product was not observed. Rather, exposure of chalcone 167 to photoredox conditions resulted in a complex mixture of products, which included cyclic dimer 168 in $24 \%$ yield. A Lewis acid screen demonstrated $\mathrm{Sm}(\mathrm{OTf})_{3}$ as an effective additive to activate the carbonyl of 167. Single electron reduction of 167 coordinated to Sm(III) generates reactive $\beta$-radical intermediate $\mathbf{1 6 9}$, which adds to another equivalent of $\mathbf{1 6 7}$ to form $\mathbf{1 7 0}$. Hydrogen atom abstraction forms enolate $\mathbf{1 7 1}$ that is subsequently protonated and undergoes an intramolecular aldol addition to form 168 in a $62 \%$ yield.

\section{Conclusion}

These transition metal- and visible light-mediated radical processes demonstrate the efforts of the synthetic organic community to develop new and efficient methods for the generation of complex molecules in both an atom- and step-economical fashion. Both transition metal and photoredox domino processes garner access to a wide variety of products. While the mechanisms illustrated here all show clear, succinct catalytic systems, it is also possible for these reactions to operate additionally through short-chain propagation. However, in all of the systems presented, a catalyst is required at a minimum for initiation. Further studies of the discrete interactions of each system might shed insight onto which mechanistic pathway is dominant. These data could provide important details necessary to expand the selection of complex transformations in this area.

\section{Acknowledgments}

Financial support from the NIH-NIGMS (R01-GM096129) the Alfred P. Sloan Foundation, the Camille and Henry Dreyfus Foundation, Amgen, Boehringer Ingelheim, Eli Lilly, Novartis and the University of Michigan is gratefully acknowledged. We would like to thank Mr. Joel Beatty, Dr. Milena Czyz, Dr. James Douglas, Mr. Mitch Keylor, Mr. Bryan Matsuura, Mr. John Nguyen, and Dr. Elizabeth Swift for their helpful discussions and suggestions.

\section{REFERENCES}

1. For reviews on these types of reactions, see: Tietze LF, Beifuss U. Angew. Chem. Int. Ed. in Engl. 1993; 32:131-163. Tietze LF. Chem. Rev. 1996; 96:115-136. Denmark SE, Thorarensen A. Chem. Rev. 1996; 96:137-166. Ryu I, Sonoda N, Curran DP. Chem. Rev. 1996; 96:177-194. Malacria M. Chem. Rev. 1996; 96:289-306. [PubMed: 11848754] Tietze LF, Brasche G, Gericke KM. Domino Reactions in Organic Synthesis. 2006Weinheim, GermanyWiley-VCH Verlag GmbH \& Co. KGaA Nicolaou KC, Edmonds DJ, Bulger PG. Angew. Chem. Int. Ed. in Engl. 2006; 45:7134-7186.

2. Trost B. Science. 1991; 254:1471-1477. [PubMed: 1962206]

3. Wender PA, Verma VA, Paxton TJ, Pillow TH. Acc. Chem. Res. 2008; 41:40-49.

4. Renaud, P.; Sibi, MP., editors. Radicals in Organic Synthesis. Wiley-VCH Verlag GmbH; Weinheim, Germany: 2001.

5. (a) Khattab MA, Elgamal MA, El-Batouti M. Fire Mater. 1996; 20:253-259.(b) O’Mahony G. Synlett. 2004:572-573.

6. (a) Molander GA. Chem. Rev. 1992; 92:29-68.(b) Snider BB. Chem. Rev. 1996; 96:339-364.

7. (a) Iqbal J, Bhatia B, Nayyar NK. Chem. Rev. 1994; 94:519-564.(b) Eckenhoff WT, Pintauer T. Cat. Rev. - Sci. Eng. 2010; 52:1-59.(c) Pintauer T. Eur. J. Inorg. Chem. 2010; 2010:2449-2460.(d) Muñoz-Molina JM, Belderrain TR, Pérez PJ. Eur. J. Inorg. Chem. 2011; 2011:3155-3164. and references therein.

8. Prier CK, Rankic DA, MacMillan DWC. Chem. Rev. 2013; 113:5322-5363. [PubMed: 23509883]

9. Kharasch MS, Arimoto FS, Nudenberg W. J. Org. Chem. 1951; 16:1556-1565. 
10. Kochi JK. Acc. Chem. Res. 1974; 7:351-360.

11. (a) Minisci F. Acc. Chem. Res. 1975; 8:165-171.(b) Minisci F, Citterio A, Giordano C. Acc. Chem. Res. 1983; 16:27-32.

12. Ford L, Jahn U. Angew. Chem. Int. Ed. in Engl. 2009; 48:6386-6389.

13. Bull JA, Hutchings MG, Quayle P. Angew. Chem. Int. Ed. in Engl. 2007; 46:1869-1872.

14. Beckwith ALJ, Schiesser CH. Tetrahedron. 1985; 41:3925-3941.

15. Yang D, Yan Y-L, Zheng B-F, Gao Q, Zhu N-Y. Org. Lett. 2006; 8:5757-5760.

16. Muñoz-Molina JM, Belderrain TR, Pérez PJ. Adv. Synth. Catal. 2008; 350:2365-2372.

17. Ricardo C, Pintauer T. Chem. Commun. 2009:3029-3031.

18. Taylor MJW, Eckenhoff WT, Pintauer T. Dalton Trans. 2010; 39:11475-11482.

19. Mori M, Oda I, Ban Y. Tetrahedron Lett. 1982; 23:5315-5318.

20. Ryu I, Kreimerman S, Araki F, Nishitani S, Oderaotoshi Y, Minakata S, Komatsu M. J. Am. Chem. Soc. 2002; 124:3812-3813.

21. Sumino S, Ui T, Ryu I. Org. Lett. 2013; 15:3142-3145.

22. Fusano A, Sumino S, Nishitani S, Inouye T, Morimoto K, Fukuyama T, Ryu I. Chemistry - A European Journal. 2012; 18:9415-9422.

23. Bloome KS, Alexanian EJ. J. Am. Chem. Soc. 2010; 132:12823-12825. [PubMed: 20804186]

24. Mizutani K, Shinokubo H, Oshima K. Org. Lett. 2003; 5:3959-3961.

25. Powell DA, Maki T, Fu GC. J. Am. Chem. Soc. 2005; 127:510-511.

26. González-Bobes F, Fu GC. J. Am. Chem. Soc. 2006; 128:5360-5361.

27. Phapale VB, Buñuel E, García-Iglesias M, Cardenas DJ. Angew. Chem. Int. Ed. in Engl. 2007; 46:8790-8795. [PubMed: 17918274]

28. Domingo V, Arteaga JF, López Pérez JL, Peláez R, Quílez del Moral JF, Barrero AF. J. Org. Chem. 2012; 77:341-350.

29. Aube J, Peng X, Wang Y, Takusagawa F. J. Am. Chem. Soc. 1992; 114:5466-5467.

30. House DA. Chem. Rev. 1962; 62:185-203.

31. Chiba S, Cao Z, Bialy, El SA, Narasaka K. Chem. Lett. 2006; 35:18-19.

32. (a) Alexiev A, Bontchev PR. Mikrochim Acta. 1970; 58:13-19.(b) Bonchev PR, Aleksiev AA. Theor Exp Chem. 1975; 9:144-147.

33. Minisci F, Bernardi R, Bertini F, Galli R, Perchinummo M. Tetrahedron. 1971; 27:3575-3579.

34. Ding C, Tu S, Yao Q, Li F, Wang Y, Hu W, Zhang A. Adv. Synth. Catal. 2010; 352:847-853.

35. (a) Seiple IB, Su S, Rodriguez RA, Gianatassio R, Fujiwara Y, Sobel AL, Baran PS. J. Am. Chem. Soc. 2010; 132:13194-13196.(b) Patel NR, Flowers RA II. J. Am. Chem. Soc. 2013; 135:46724675. [PubMed: 23477364]

36. Lockner JW, Dixon DD, Risgaard R, Baran PS. Org. Lett. 2011; 13:5628-5631.

37. Shundrin LA, Bardin VV, Frohn H-J. Z. anorg. allg. Chem. 2004; 630:1253-1257.

38. Graham TH, Jones CM, Jui NT, MacMillan DWC. J. Am. Chem. Soc. 2008; 130:16494-16495.

39. Conrad JC, Kong J, Laforteza BN, MacMillan DWC. J. Am. Chem. Soc. 2009; 131:11640-11641.

40. (a) Jui NT, Lee ECY, MacMillan DWC. J. Am. Chem. Soc. 2010; 132:10015-10017.(b) Jui NT, Garber JAO, Finelli FG, MacMillan DWC. J. Am. Chem. Soc. 2012; 134:11400-11403. [PubMed: 22764834]

41. Rendler S, MacMillan DWC. J. Am. Chem. Soc. 2010; 132:5027-5029.

42. For additional reviews on visible light photoredox catalysis, see: Narayanam JMR, Stephenson CRJ. Chem. Soc. Rev. 2010; 40:102. Teplý F. Collect. Czech. Chem. Commun. 2011; 76:859917. Tucker JW, Stephenson CRJ. J. Org. Chem. 2012; 77:1617-1622. Yoon TP. ACS Catal. 2013; 3:895-902.

43. Zhu C, Xie J, Xu P, Li H, Xue Q, Jin H, Yixiang C. Chem. Commun. 2013; 49:5672-5674.

44. Hari DP, Hering T, König B. Org. Lett. 2012; 14:5334-5337.

45. Xiao T, Dong X, Tang Y, Zhou L. Adv. Synth. Catal. 2012; 354:3195-3199.

46. Narayanam JMR, Tucker JW, Stephenson CRJ. J. Am. Chem. Soc. 2009; 131:8756-8757.

47. Tucker JW, Narayanam JMR, Krabbe SW, Stephenson CRJ. Org. Lett. 2010; 12:368-371. 
48. Curran DP, Rakiewicz DM. J. Am. Chem. Soc. 1985; 107:1448-1449.

49. Tanabe Y, Nishii Y, Wakimura K-I. Chem. Lett. 1994:1757-1760.

50. Tucker JW, Nguyen JD, Narayanam JMR, Krabbe SW, Stephenson CRJ. Chem. Commun. 2010; 46:4985.

51. Tucker JW, Stephenson CRJ. Org. Lett. 2011; 13:5468-5471. [PubMed: 21939250]

52. Ischay MA, Anzovino ME, Du J, Yoon TP. J. Am. Chem. Soc. 2008; 130:12886-12887. [PubMed: 18767798]

53. Hurtley AE, Cismesia MA, Ischay MA, Yoon TP. Tetrahedron. 2011; 67:4442-4448.

54. Lu Z, Shen M, Yoon TP. J. Am. Chem. Soc. 2011; 133:1162-1164.

55. Zhao G, Yang C, Guo L, Sun H, Lin R, Xia W. J. Org. Chem. 2012; 77:6302-6306. [PubMed: 22731518] 

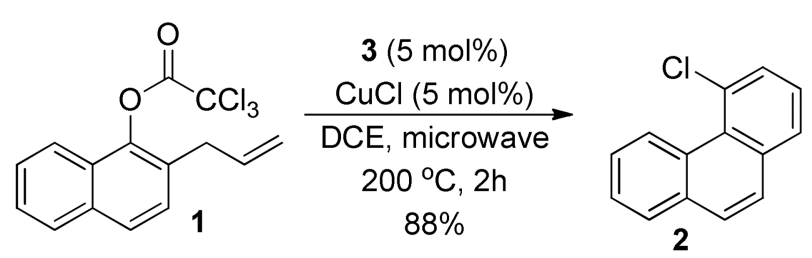<smiles>Cl[n+]1ccn(Cc2ccccn2)c1</smiles>
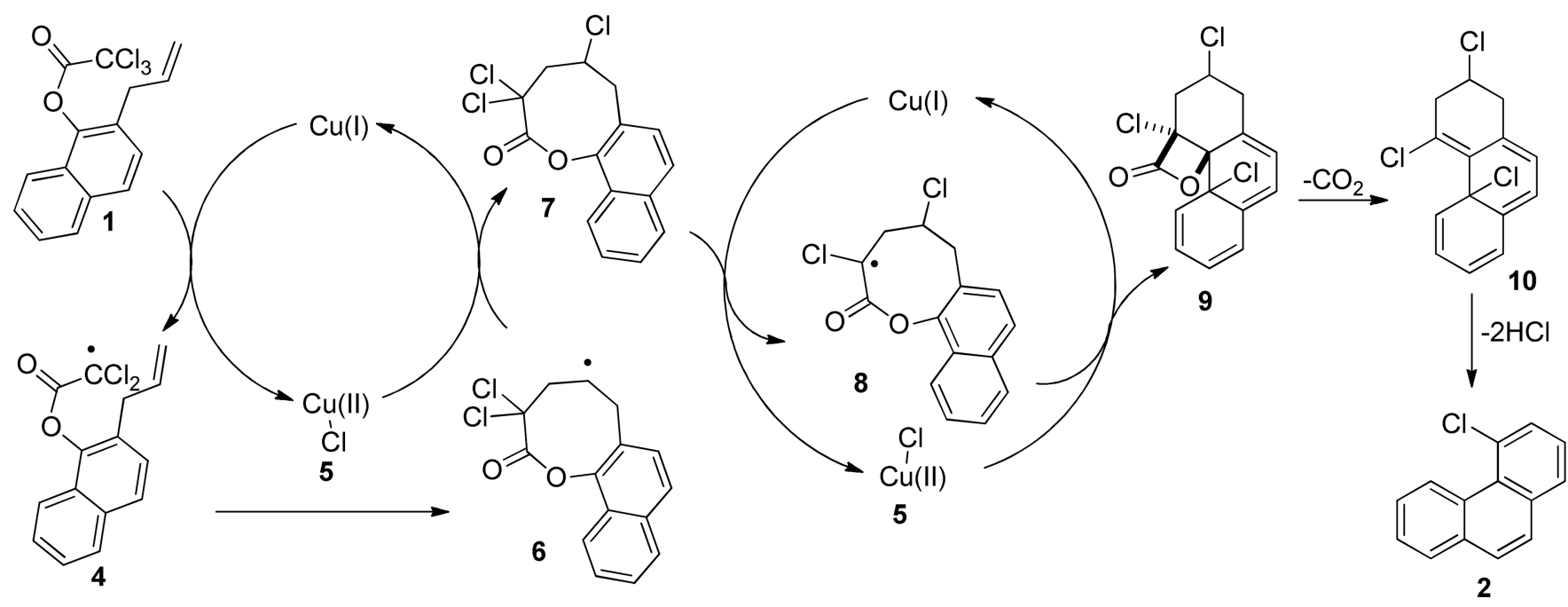

Figure 1.

Cu-mediated domino benzannulation of $\mathbf{1}$ and mechanism. 

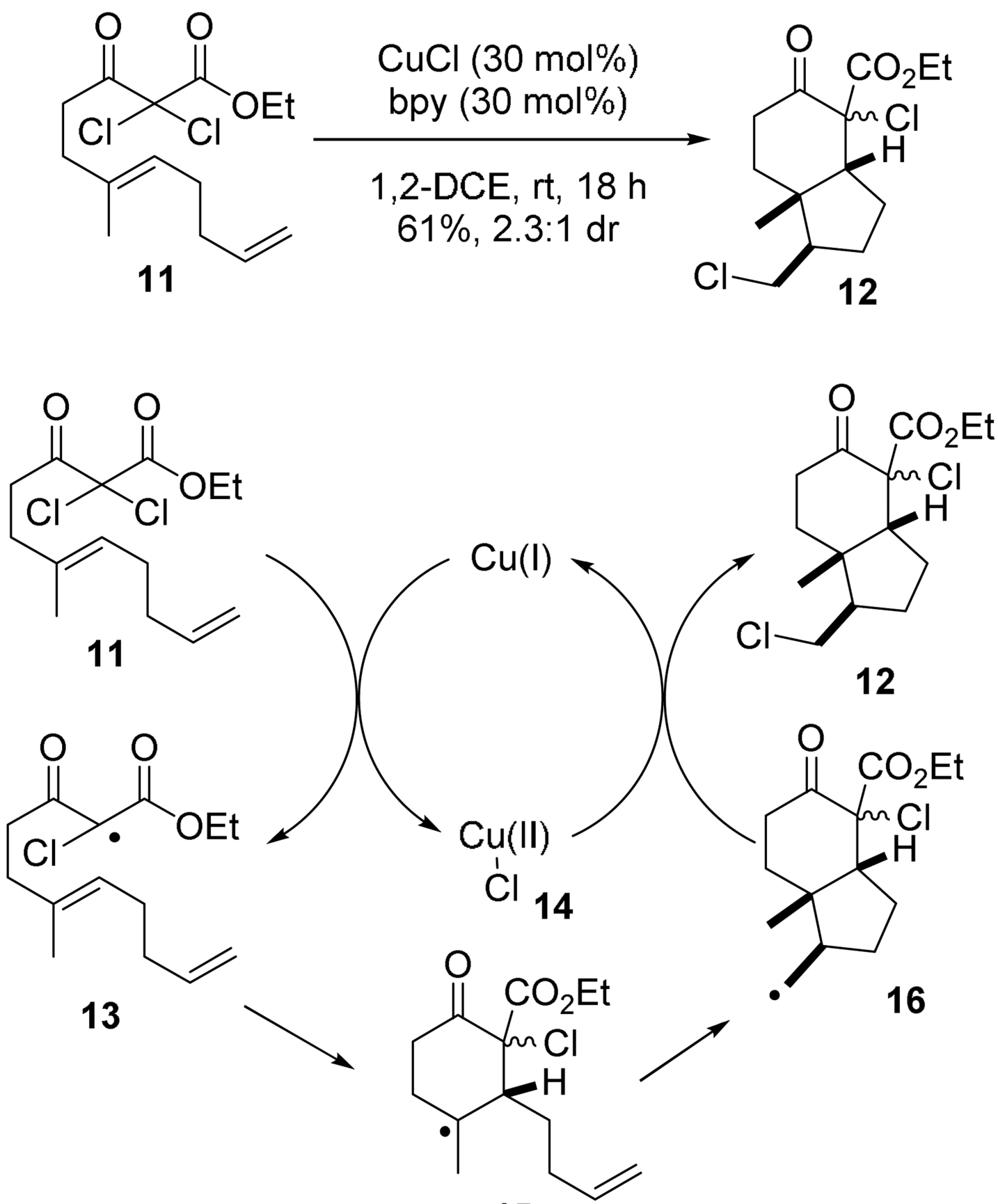

15

Figure 2.

Cu-mediated ATRC of 11 and mechanism. 
<smiles>C=CCC(CC=C)(C(=O)OCC)C(=O)OCC</smiles>

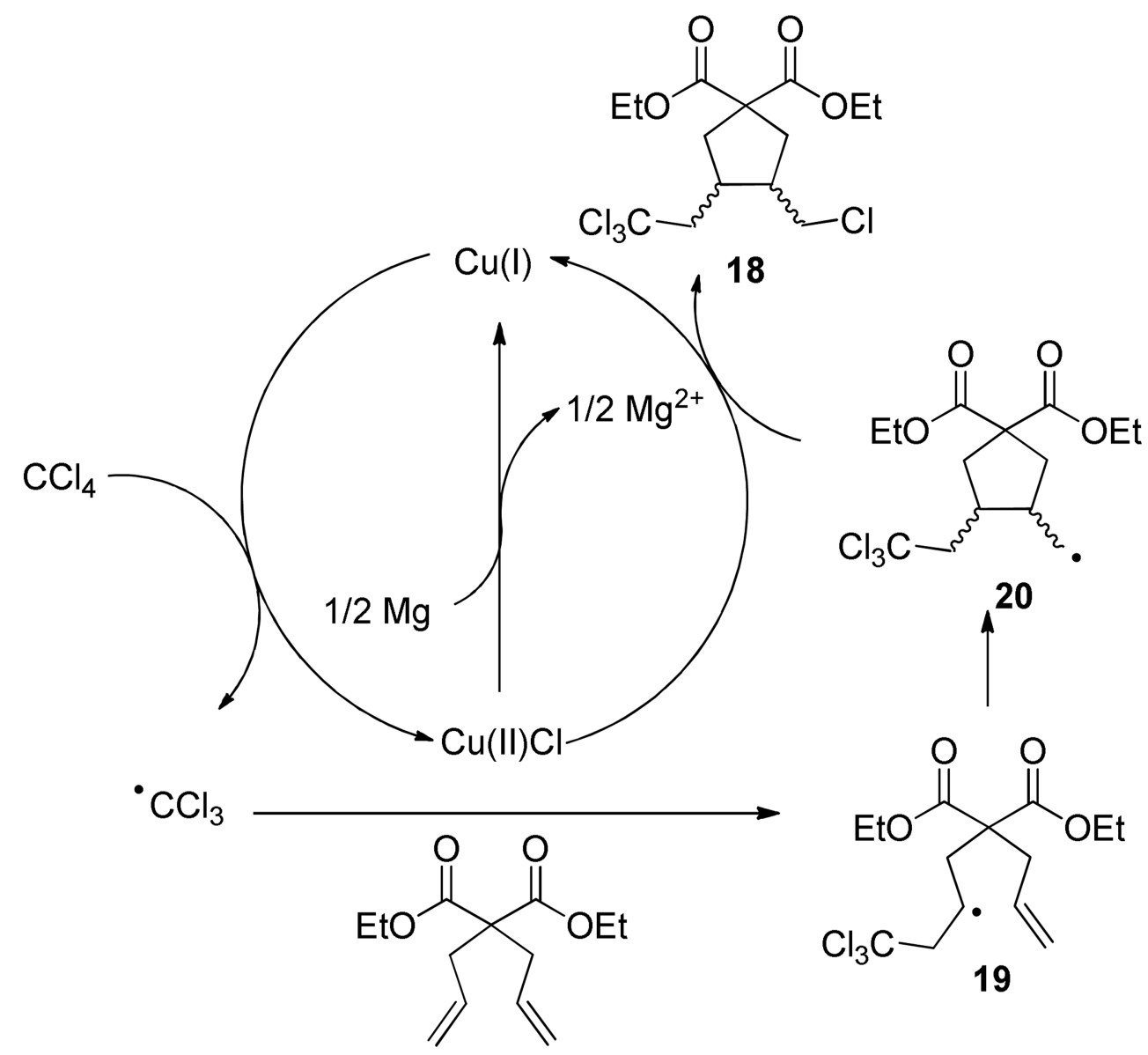

17

Figure 3.

$\mathrm{Cu}$-mediated radical addition/cyclization of $\mathbf{1 7}$ and mechanism. 

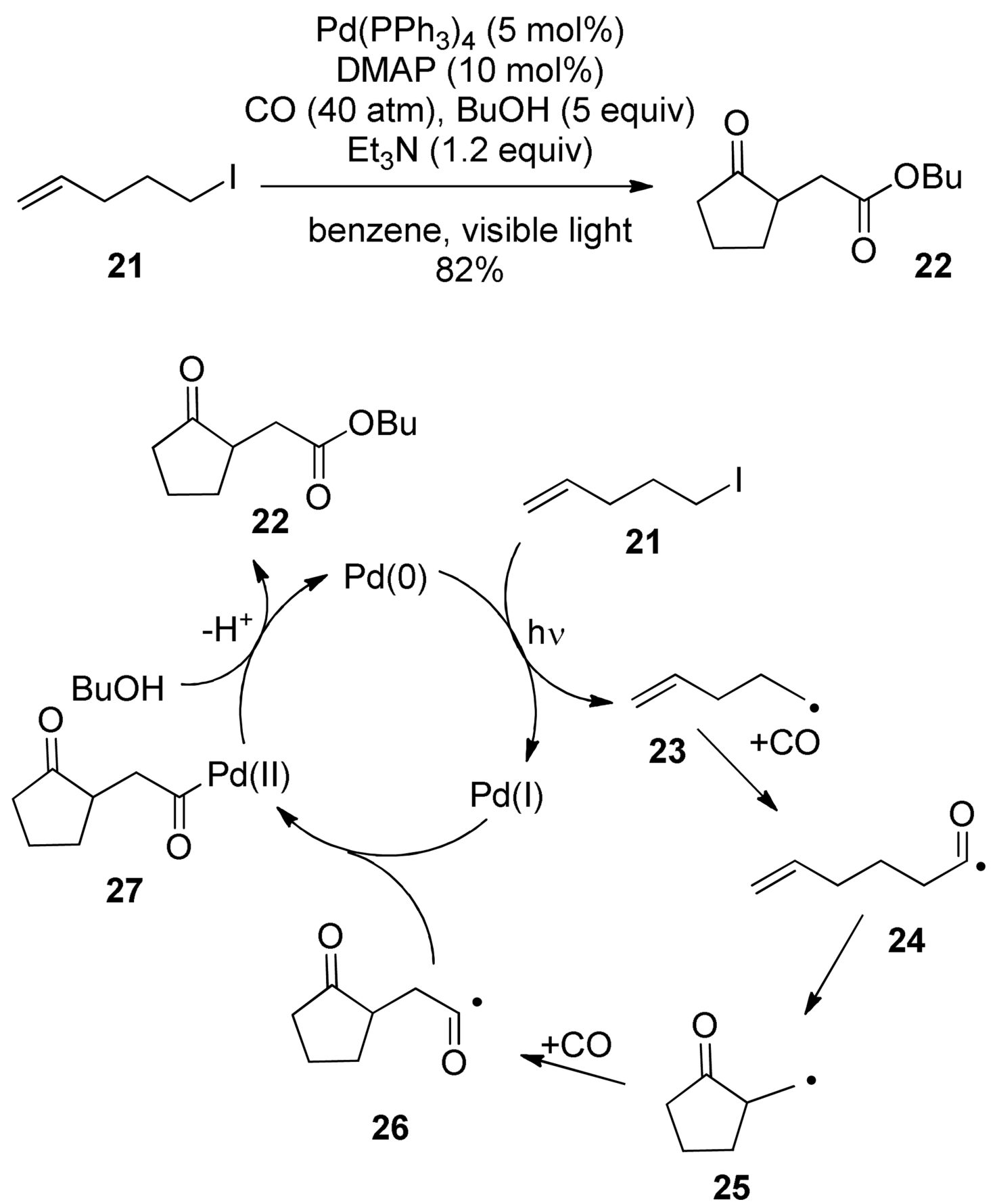

Figure 4.

Pd-mediated radical cyclization and carbonylation of $\mathbf{2 1}$ and mechanism. 


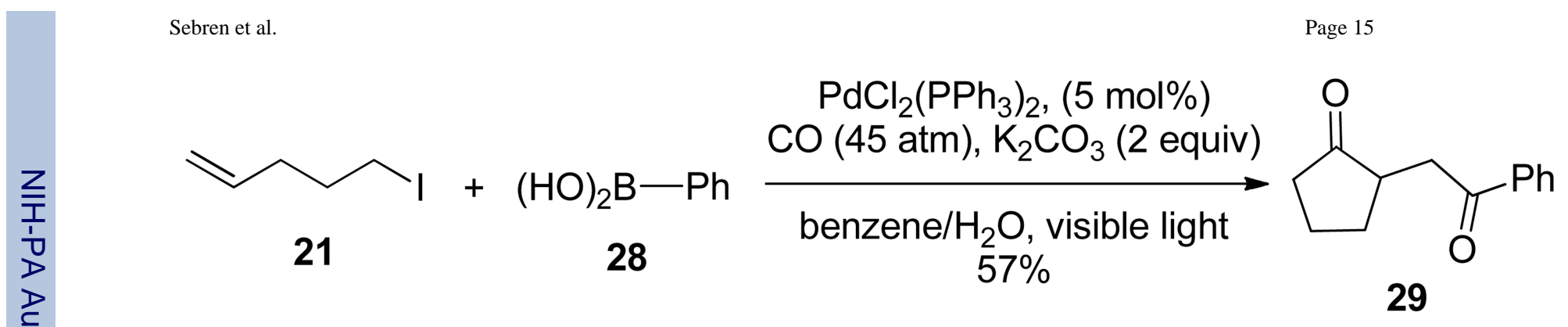

Figure 5.

Pd-mediated radical cyclization, carbonylation, and arylation of 21. 
<smiles>C=CCCCOCCCCC1CCCOC1=O</smiles><smiles>CCOC(=O)CCC1CCCOC1=O</smiles>

Figure 6.

Pd-mediated radical addition and carbonylation of $\mathbf{3 0}$. 

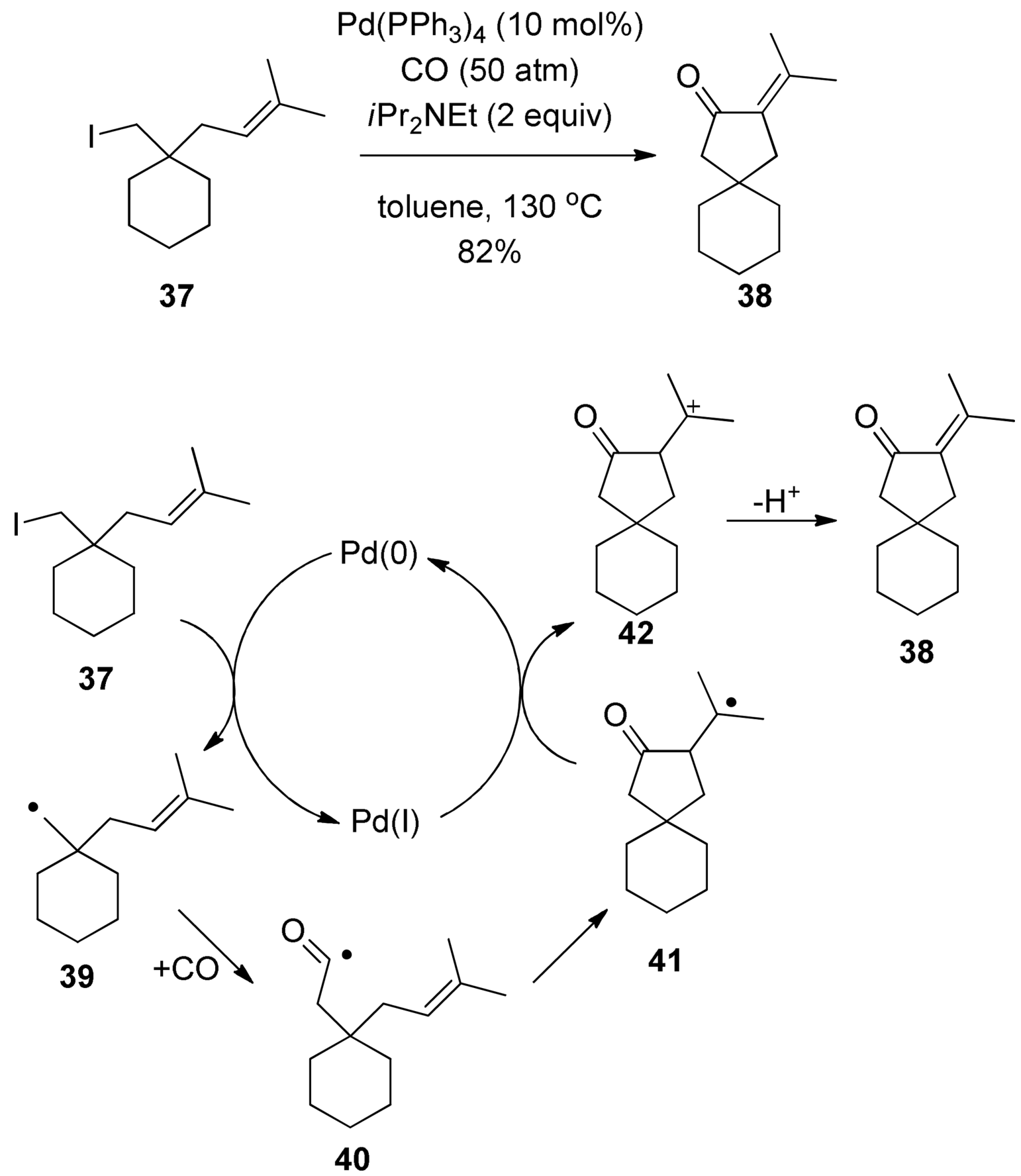

Figure 7.

Pd-catalyzed radical cyclization and carbonylation of $\mathbf{3 7}$ and mechanism. 

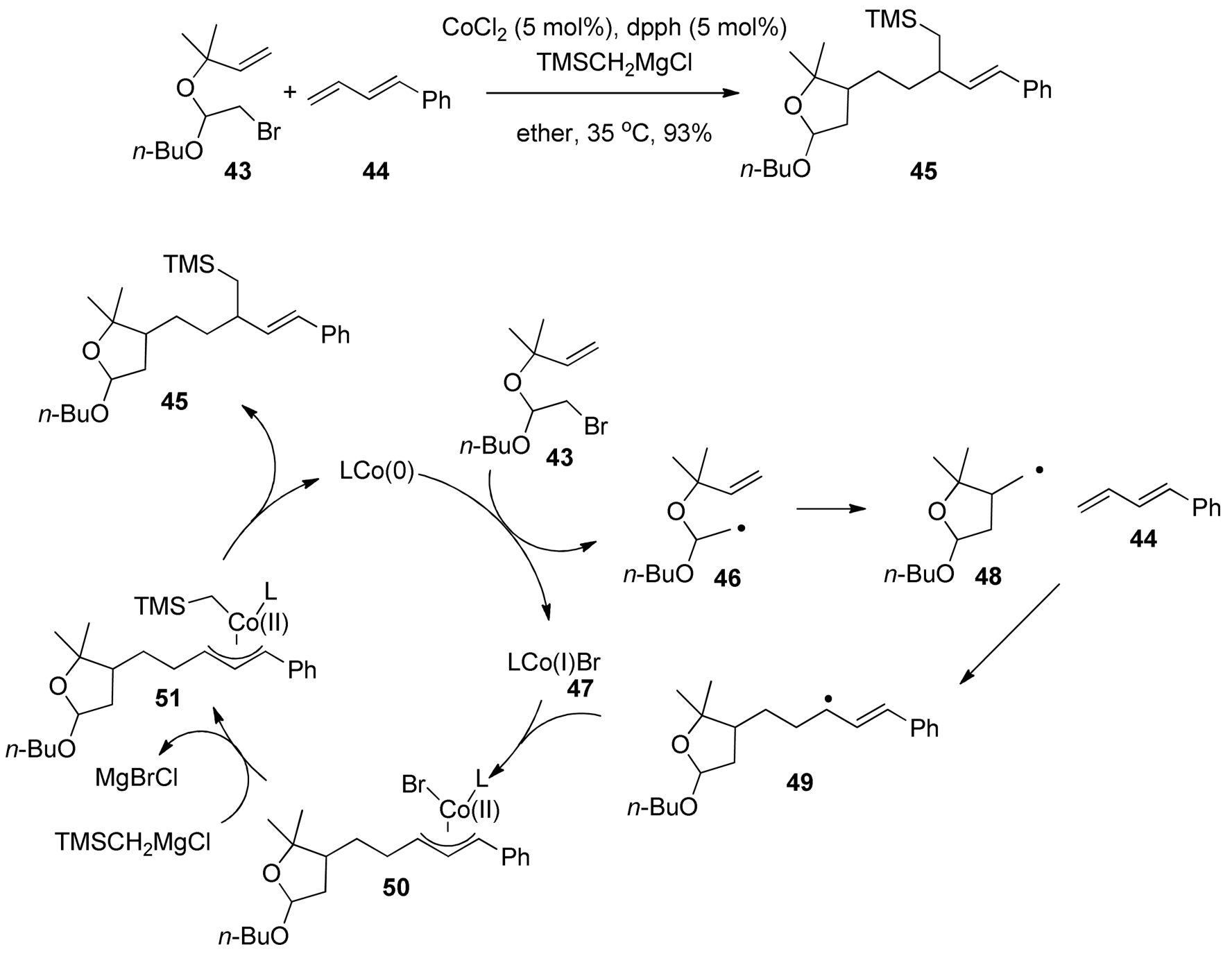

Figure 8.

Co-catalyzed radical cyclization-Tsuji-Trost allylation of $\mathbf{4 3}$ and mechanism. 
<smiles>[X]C1CCC1Br</smiles>

52

53<smiles>[X]C1CCC(Br)C1O[CH+]C=C</smiles>

52
55

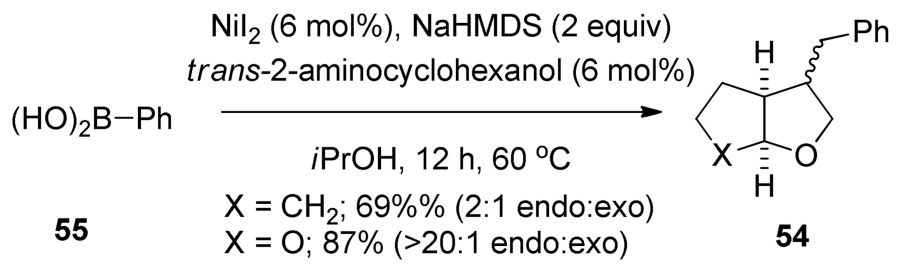

$\mathrm{NiCl}_{2}(10 \mathrm{~mol} \%)$, bpy (15 mol\%)

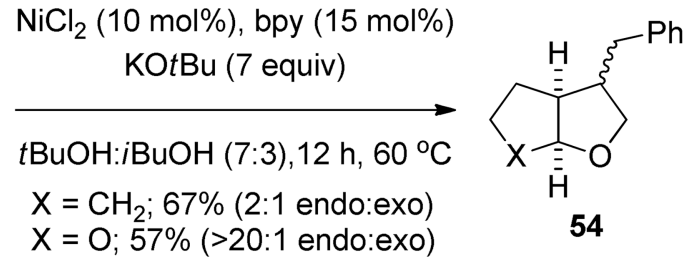

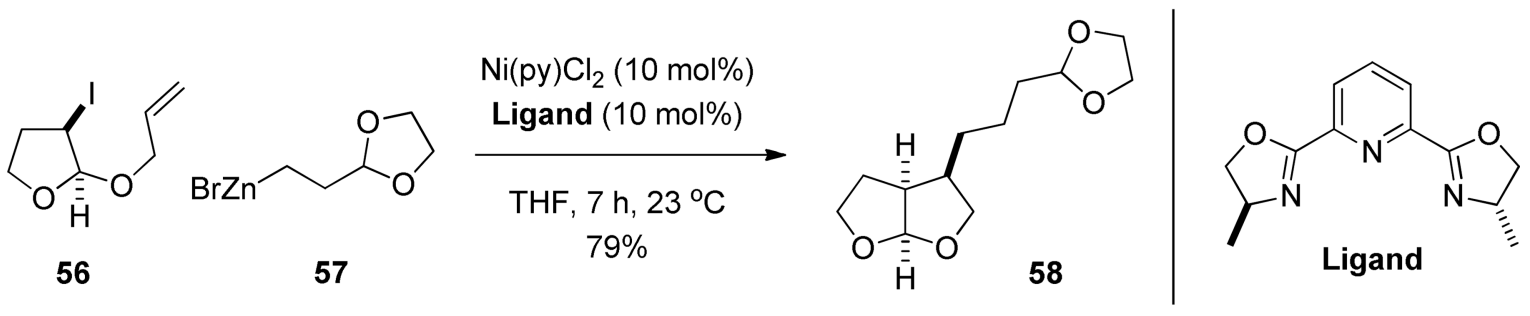

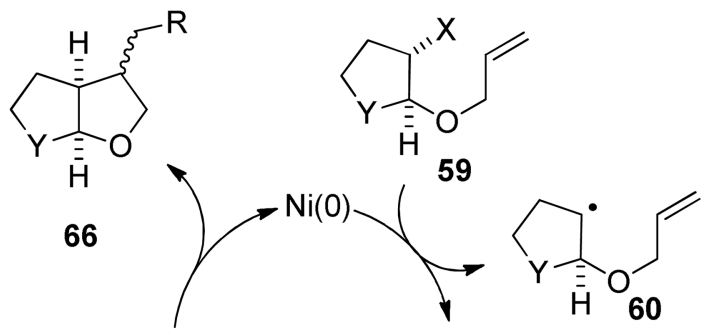

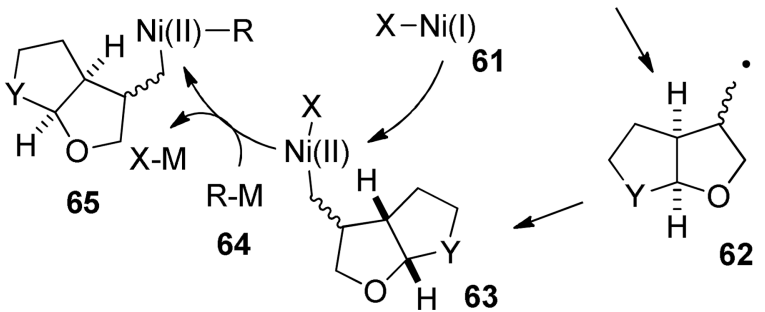

Figure 9.

Ni-catalyzed radical cyclization-Stille coupling of $\mathbf{5 2}$, Ni-catalyzed radical cyclizationSuzuki coupling of 52, Ni-catalyzed radical cyclization-Negishi coupling of $\mathbf{5 6}$ and their mechanism. 


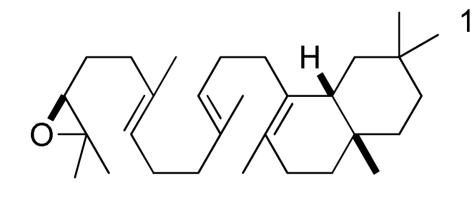

67

1) $\mathrm{Cp}_{2} \mathrm{TiCl}_{2}(30 \mathrm{~mol} \%), \mathrm{Mn}$ (8 equiv), collidine ( 7 equiv), TMSCl (4 equiv)

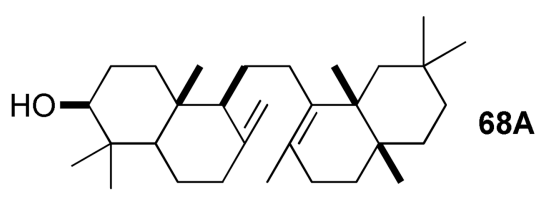
THF, rt, $3 \mathrm{~h}$

2) TBAF, THF, rt $44 \% 68 \mathrm{~A}$ and $8 \% 68 \mathrm{~B}$
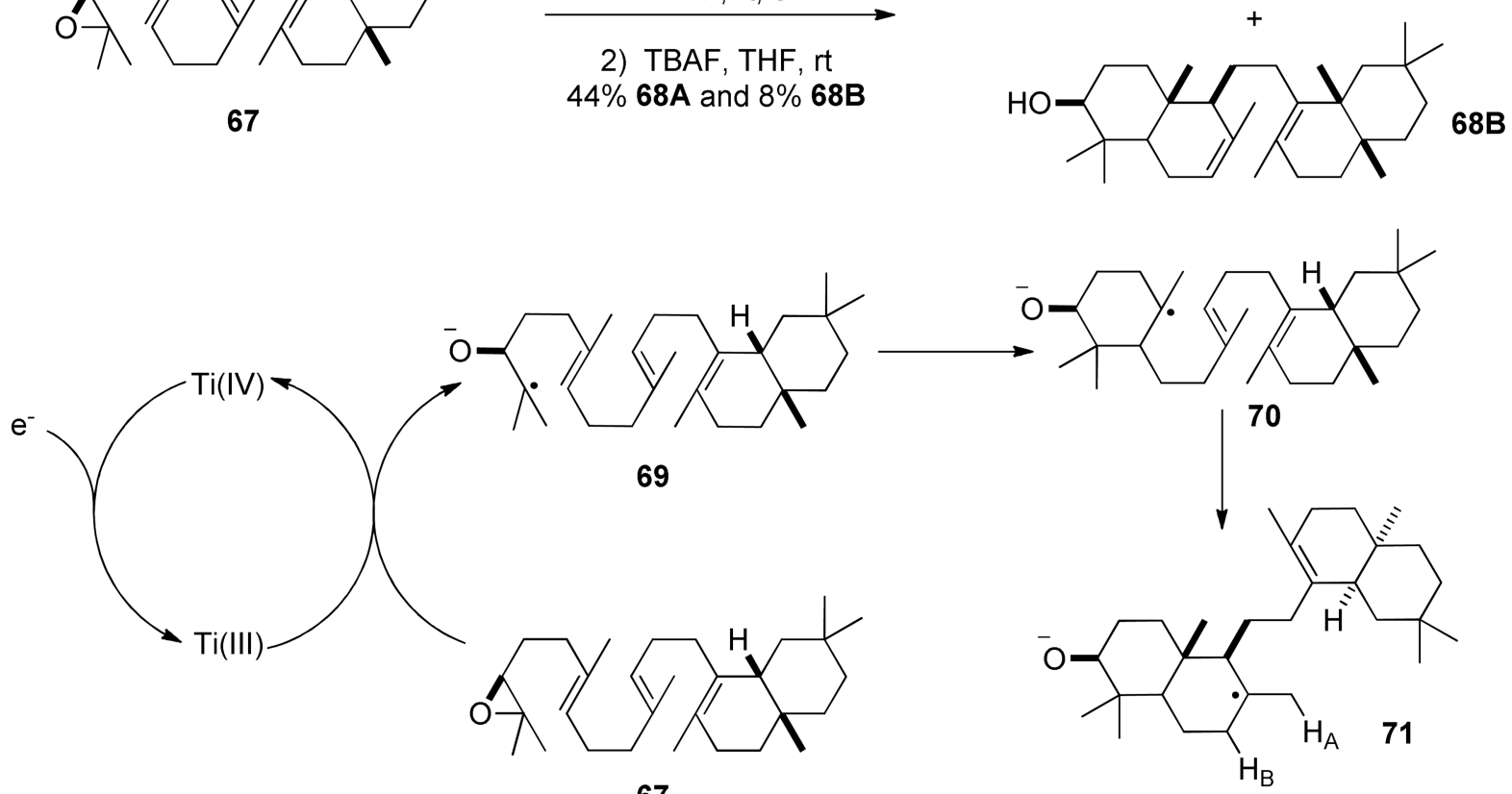

67

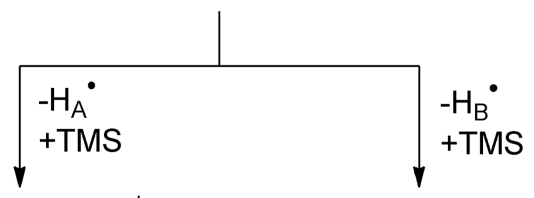

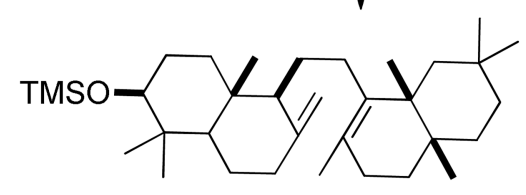

TMS-68A

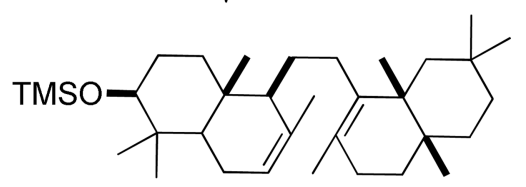

TMS-68B

Figure 10.

Ti-catalyzed reductive polyene cyclization of $\mathbf{6 7}$ and mechanism. 
<smiles>C=CCC[C@@]1(P)ON1C(P)=[W]</smiles>

72

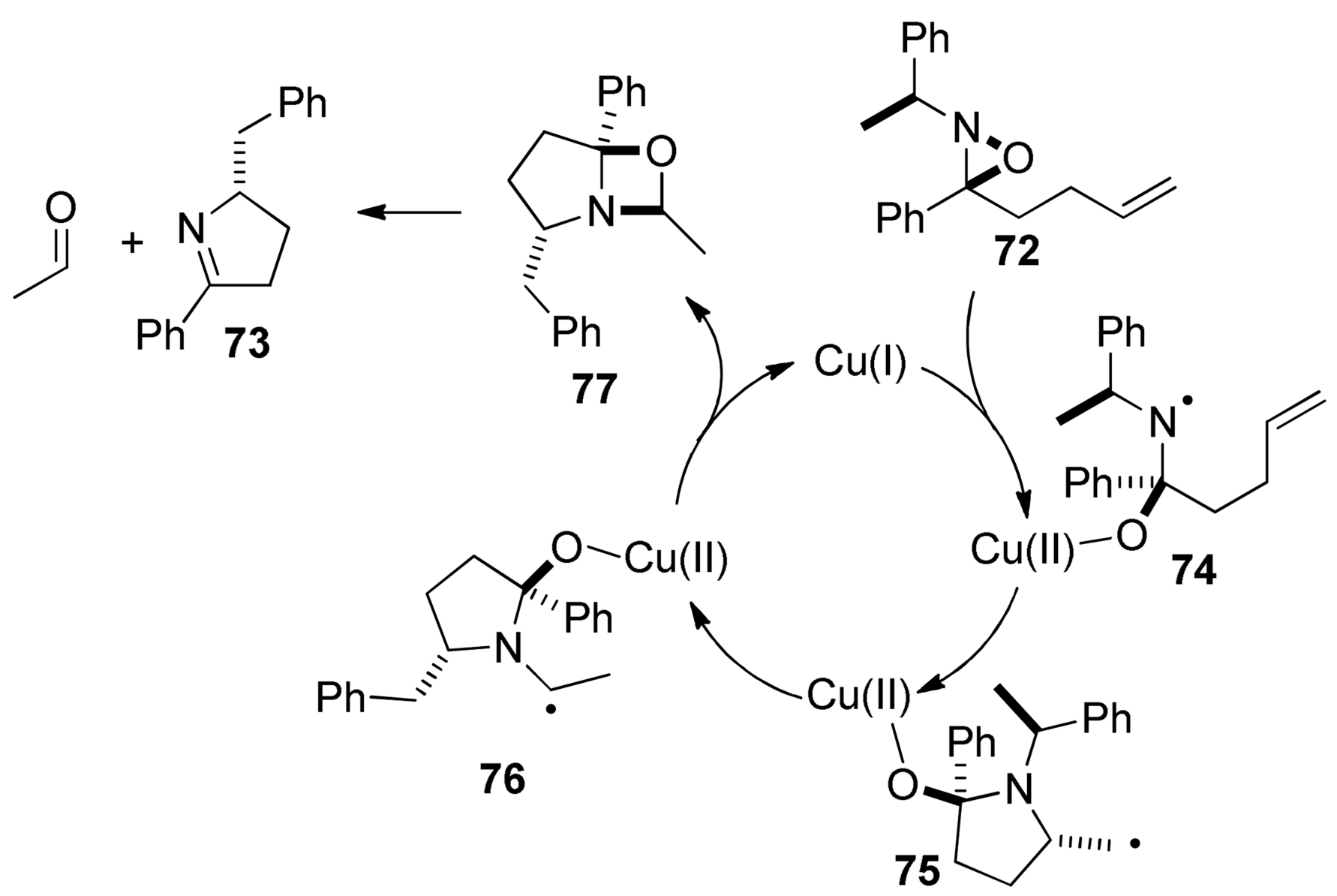

$\left[\mathrm{Cu}\left(\mathrm{PPh}_{3}\right) \mathrm{Cl}\right]_{4}(5 \mathrm{~mol} \%)$

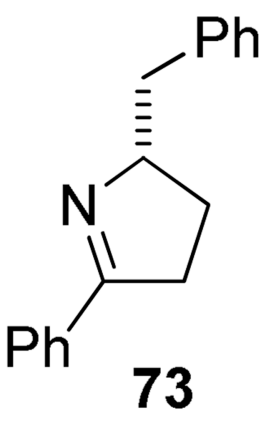
$66 \%,>95 \%$ ee

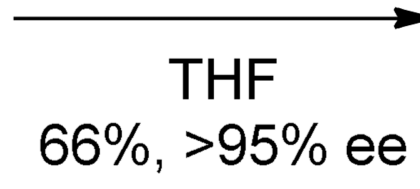

$\mathrm{Ph} 73$

\section{THF}

Figure 11.

$\mathrm{Cu}$-catalyzed redox neutral rearrangement of $\mathbf{7 2}$ and mechanism. 
<smiles>C=CCCc1nc([18OH])nc(C)c1C(=O)O</smiles>

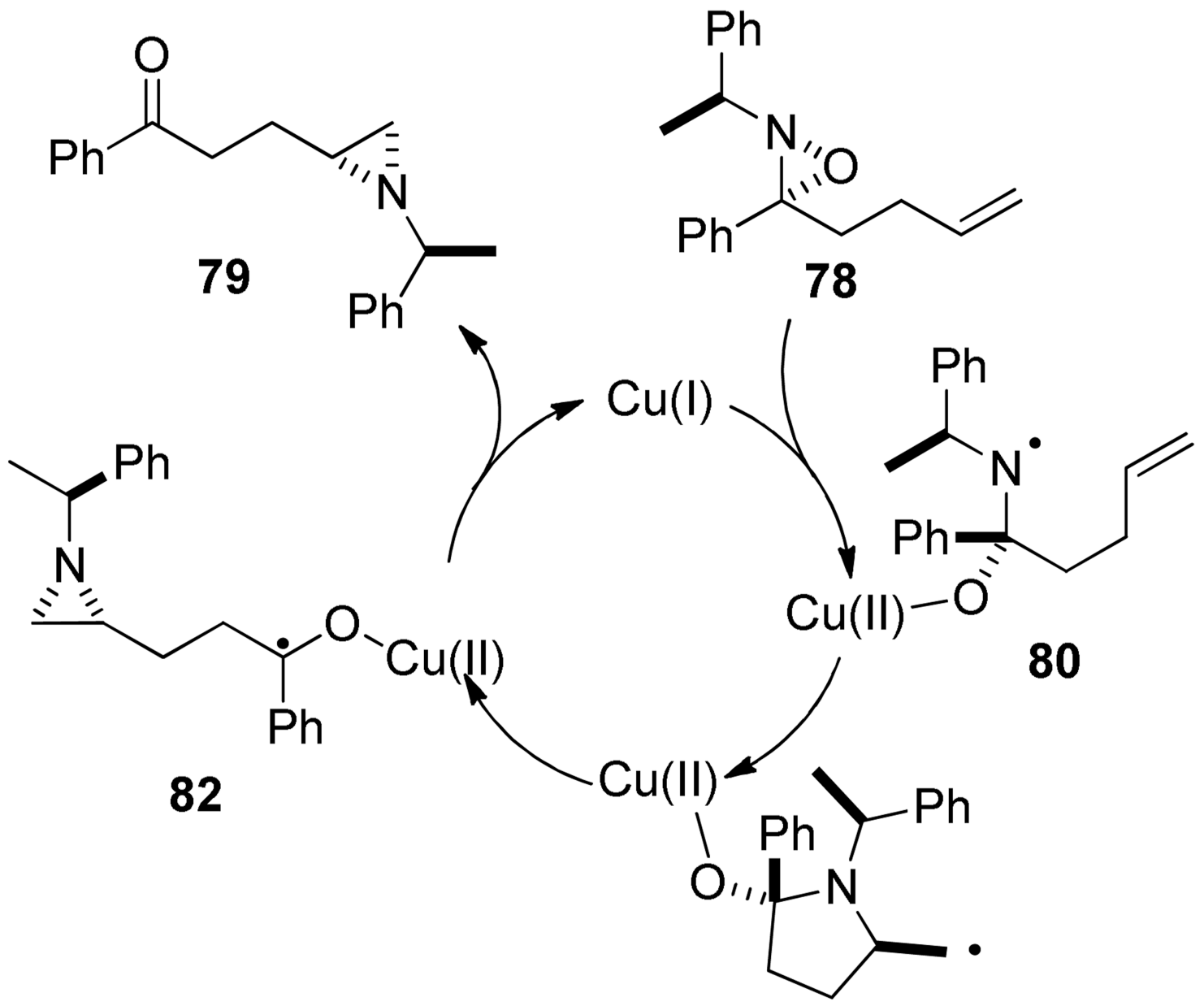

81

Figure 12.

$\mathrm{Cu}$-catalyzed redox neutral rearrangement of $\mathbf{7 8}$ and mechanism. 

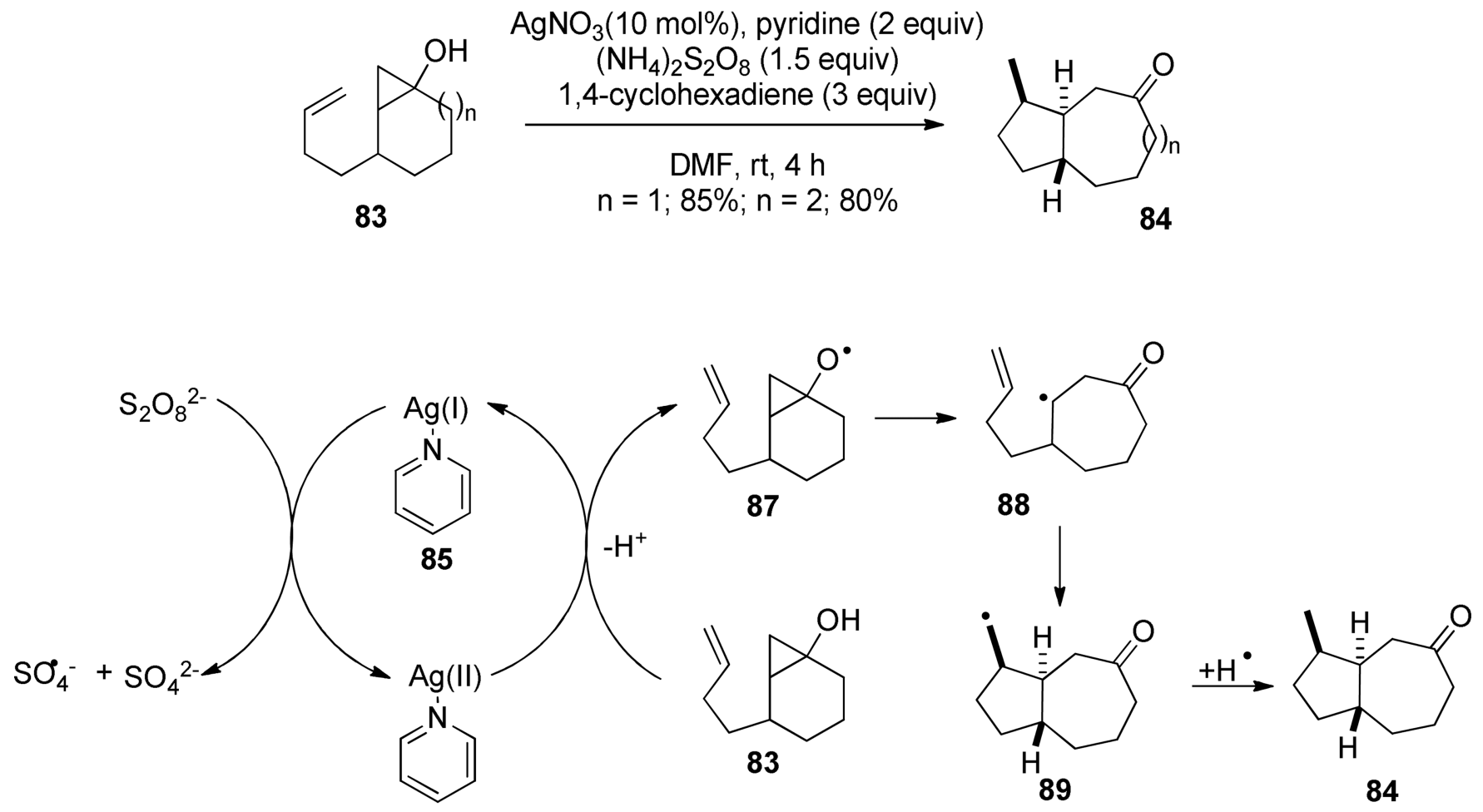

86

Figure 13.

Ag-catalyzed oxidative fragmentation/cyclization of $\mathbf{8 3}$ and mechanism. 
<smiles>COc1cccc2c1C(=O)C(Br)=CC2=O</smiles><smiles>CCc1cn(C)c2ccccc12</smiles>

Figure 14.

Ag-catalyzed Minisci/cyclization of $\mathbf{9 0}$ and $\mathbf{9 1}$ and mechanism. 

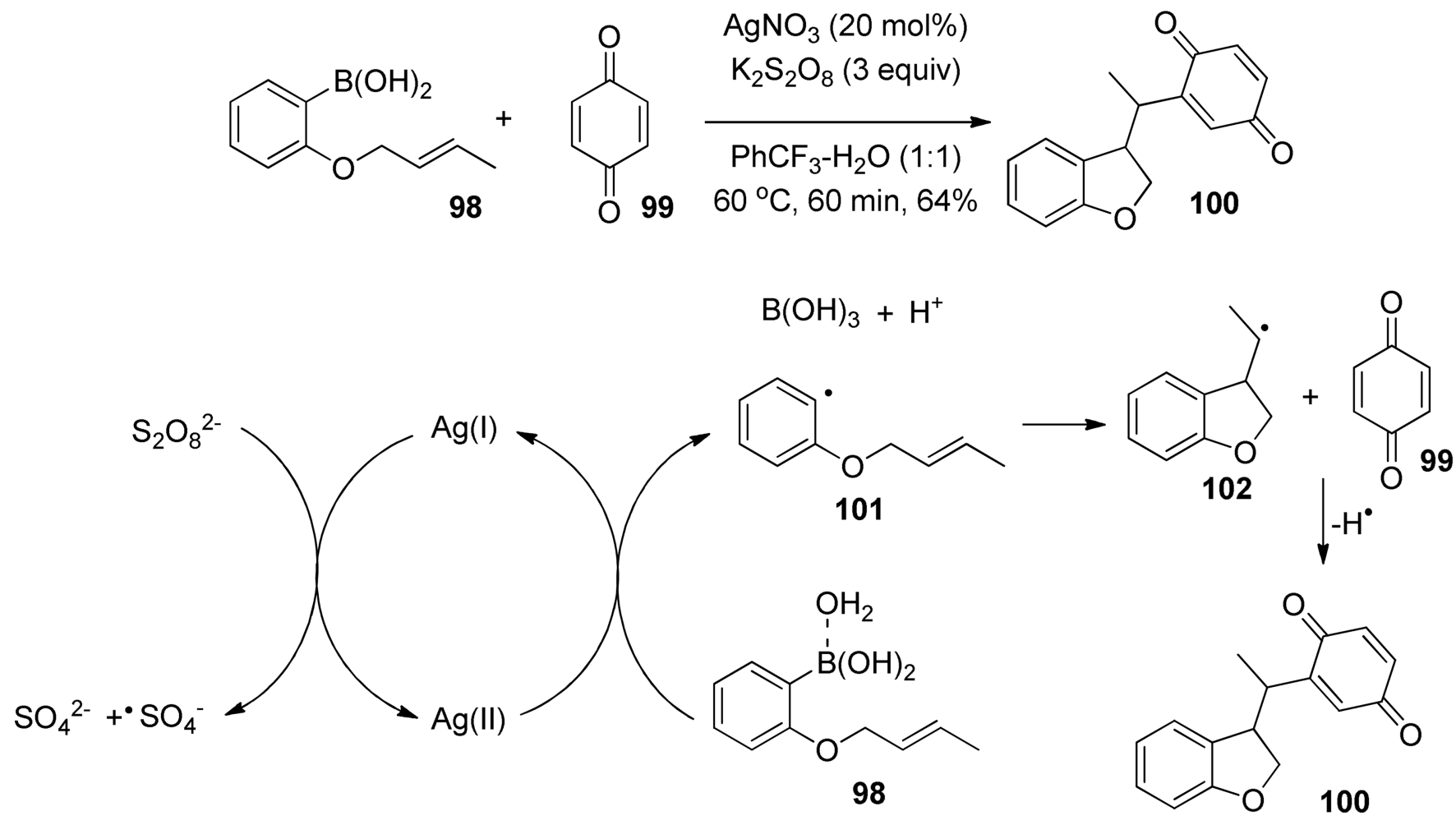

Figure 15.

Ag-catalyzed oxidative cyclization of 98 and addition to 99 and mechanism. 


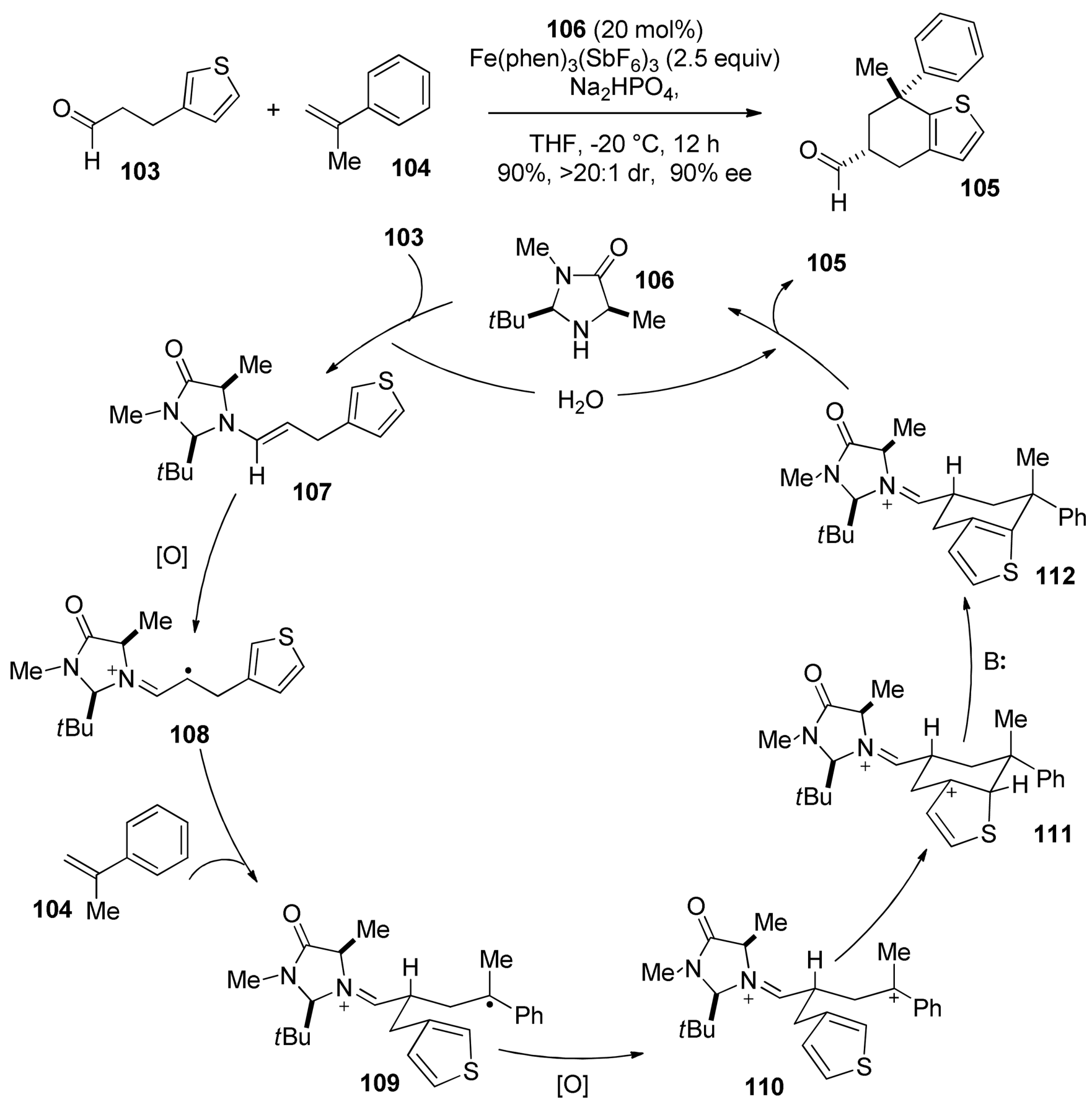

Figure 16.

Fe(III)-mediated organo-SOMO cycloaddition of 103 and 104 with mechanism. 

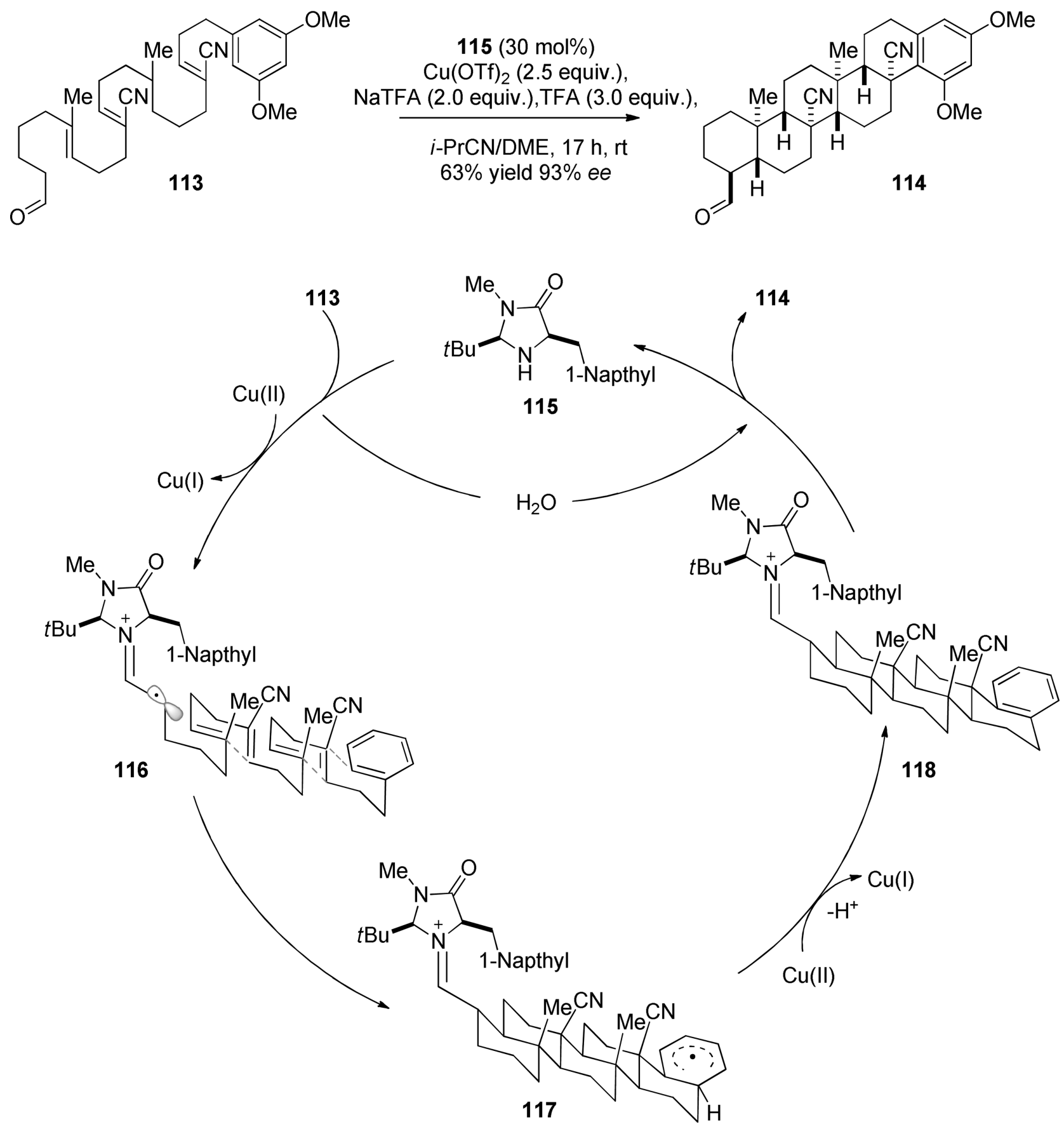

Figure 17.

$\mathrm{Cu}$ (II)-mediated organo-SOMO polyene cyclization of $\mathbf{1 1 3}$ and mechanism. 


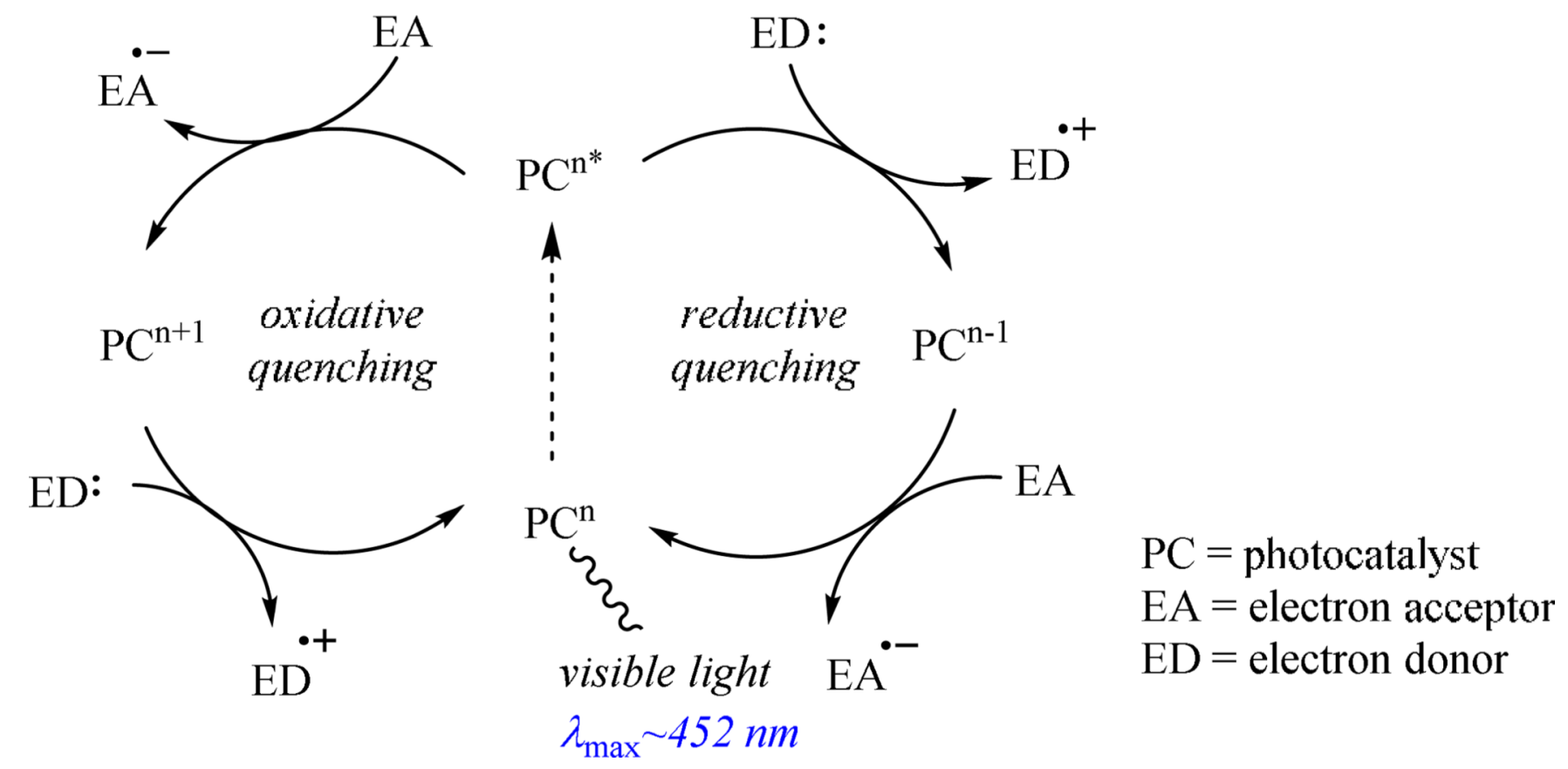

Figure 18.

General photoredox paradigm. 
<smiles>C=C(C)C(=O)N(C)c1ccccc1</smiles>

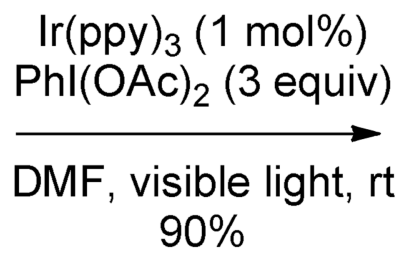

Figure 19.
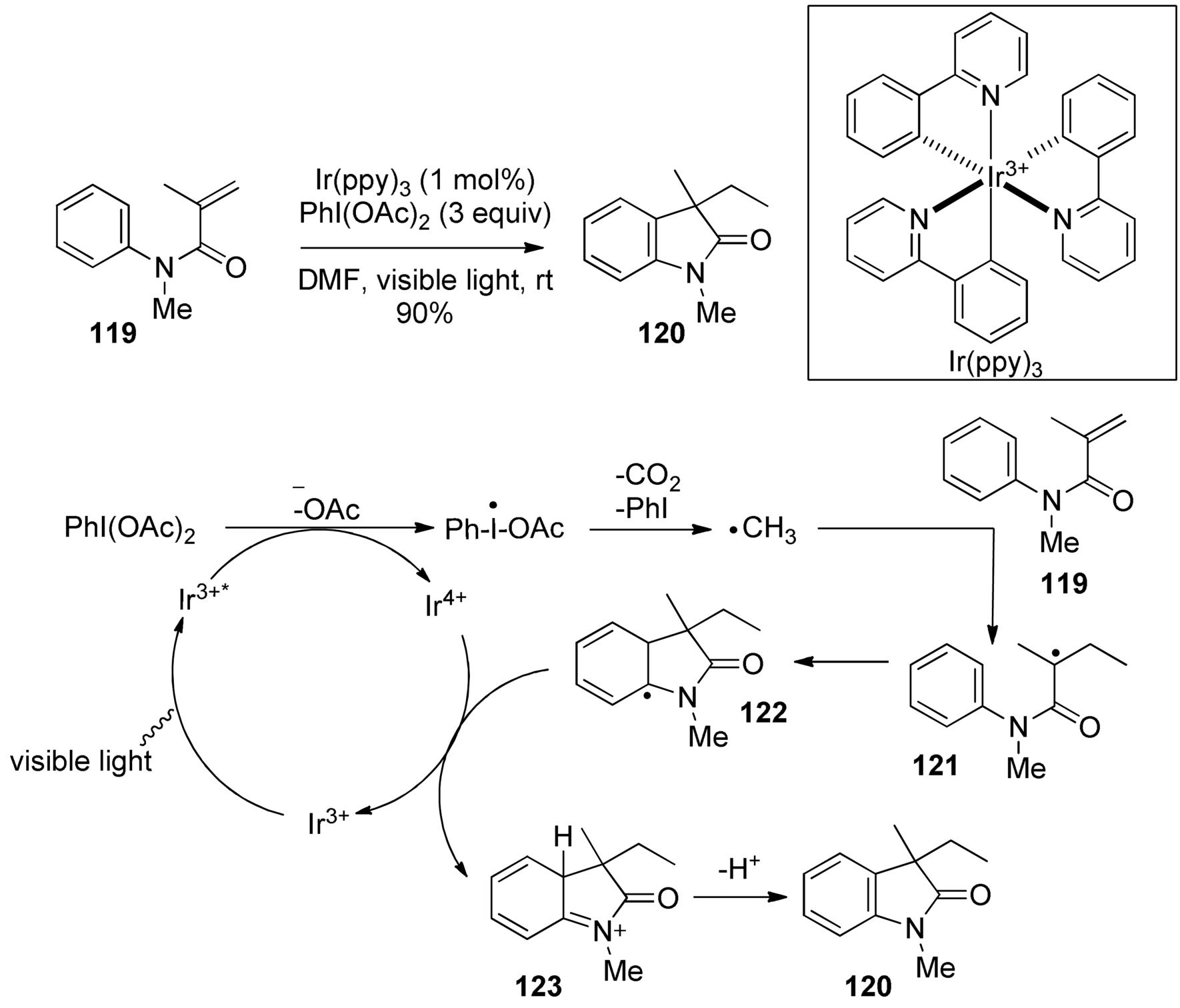

Visible light-mediated methyl transfer to $\mathbf{1 1 9}$ and cyclization and mechanism. 
<smiles>C#Cc1ccc([N+](=O)[O-])cc1</smiles><smiles>C#Cc1ccc([N+](=O)[O-])cc1</smiles>

Figure 20.

Visible light-mediated reduction/addition/cyclization of $\mathbf{1 2 4}$ and $\mathbf{1 2 5}$ and mechanism. 


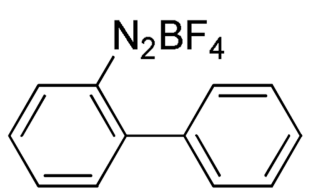

131

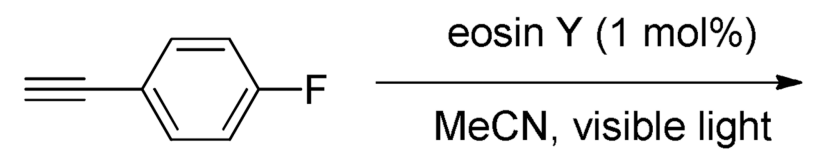

132 $82 \%$
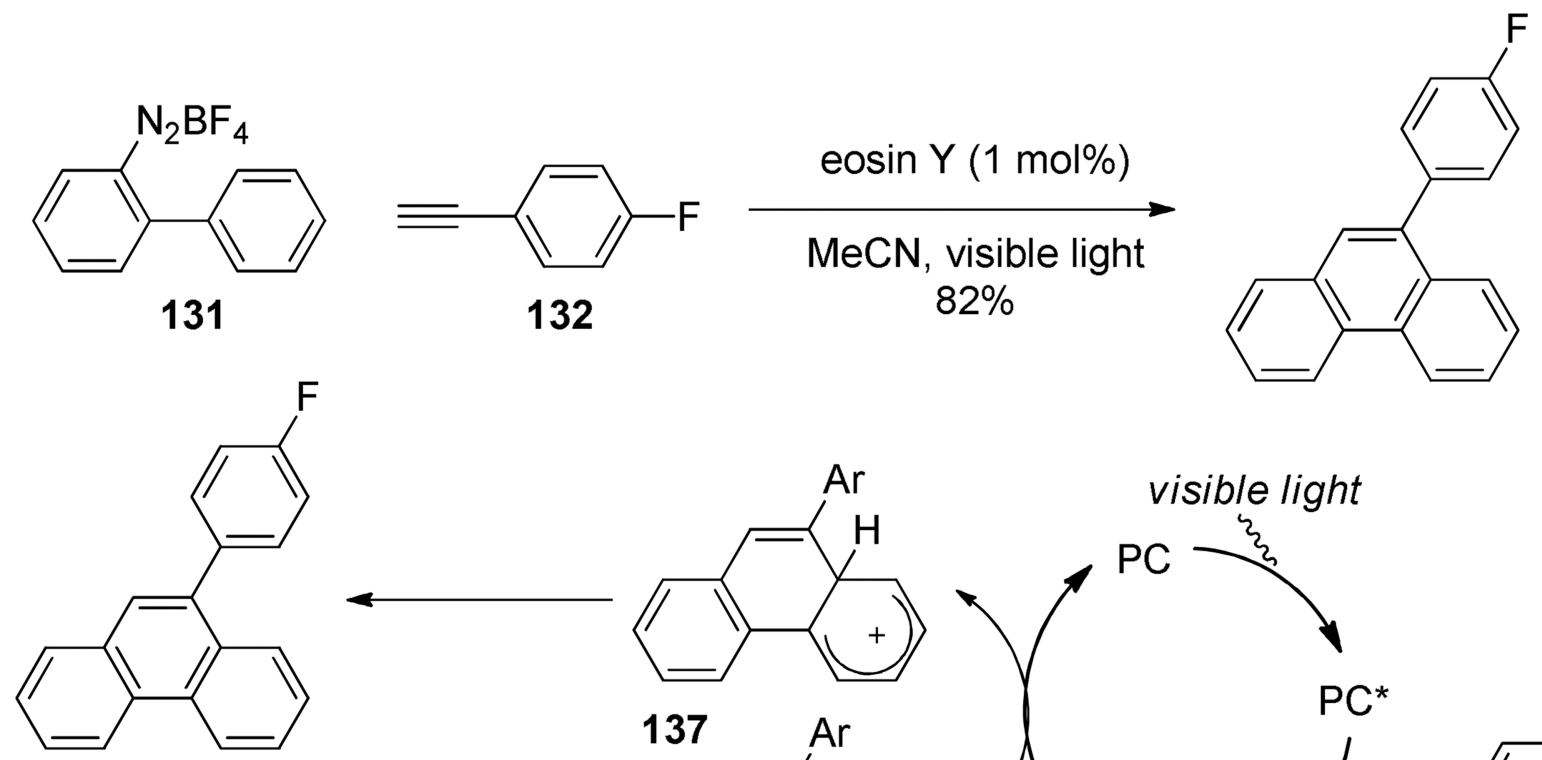

133
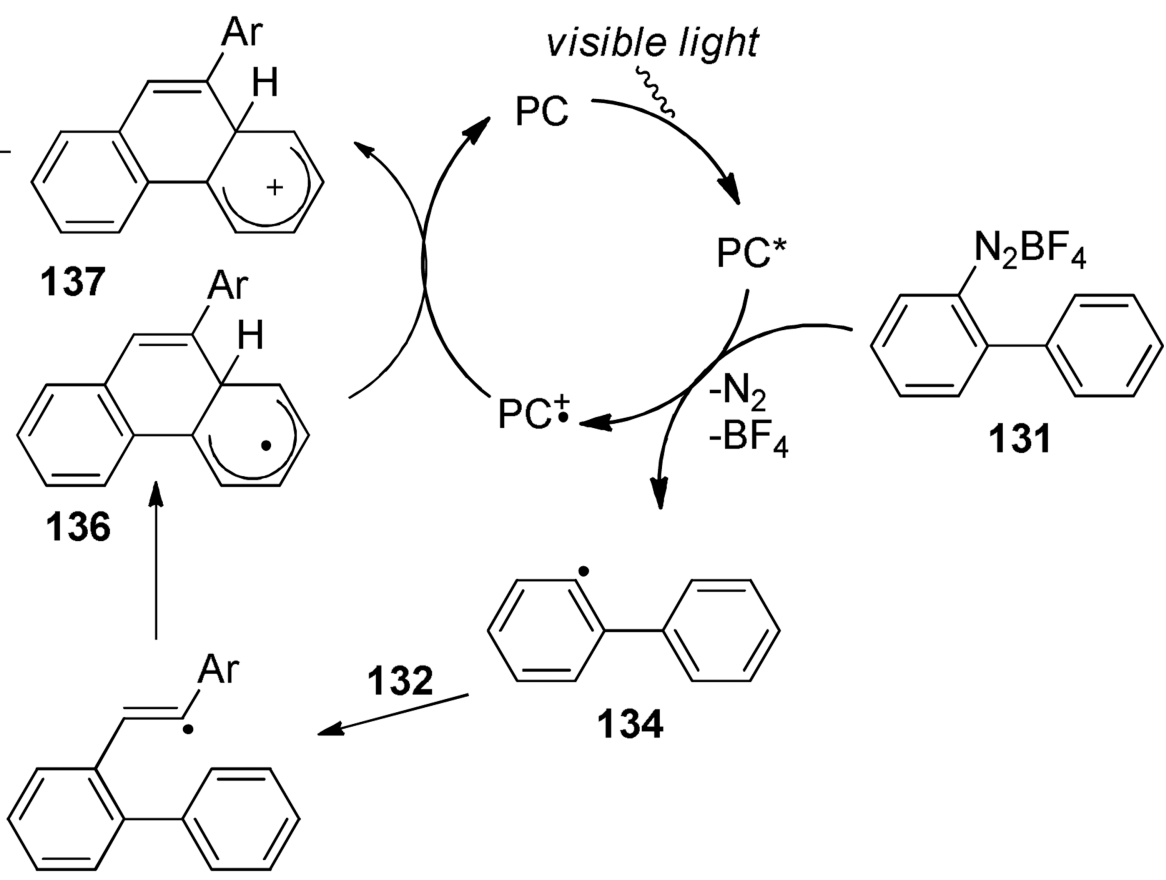

132

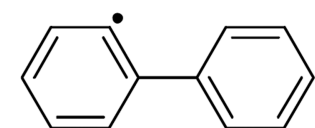

134

Figure 21.

Visible light-mediated reductive benzannulation of 131 and 132 and mechanism. 


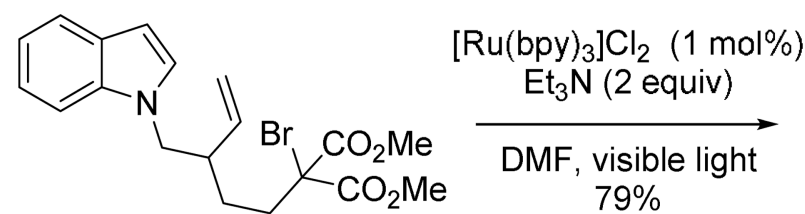

138

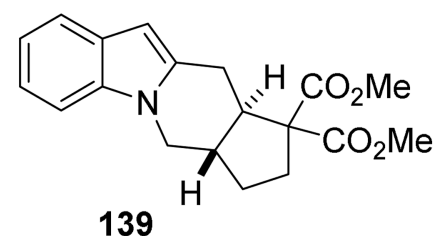

139<smiles>C=CC(CCC(Br)(CC)C(=O)OC)Cn1ccc2ccccc21</smiles>

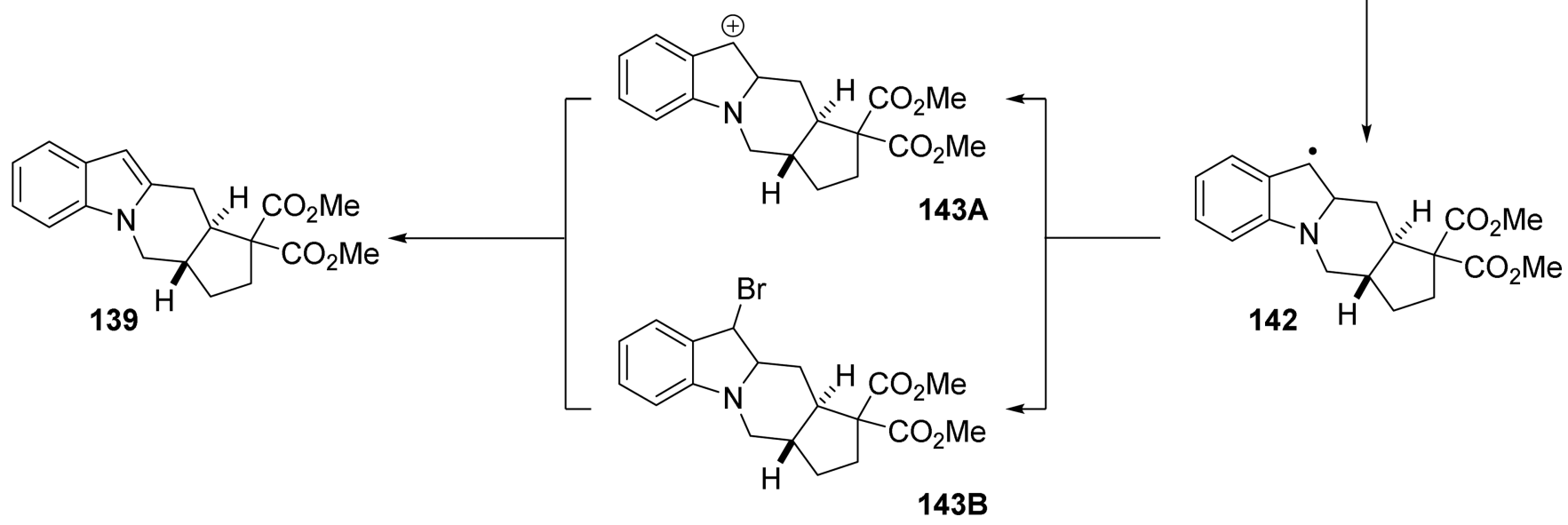

Figure 22.

Visible light-mediated ATRC of $\mathbf{1 3 8}$ and mechanism. 

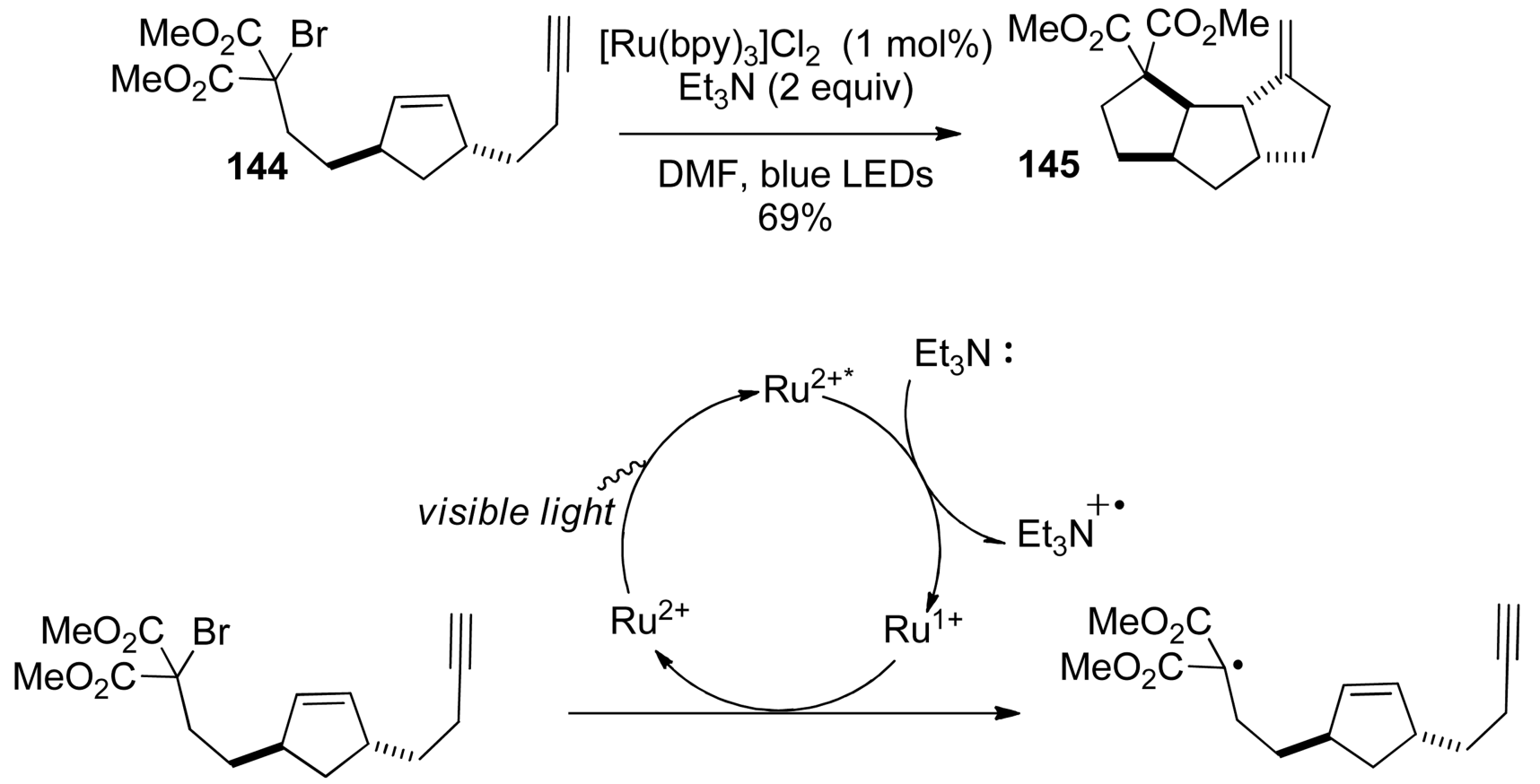

144

146
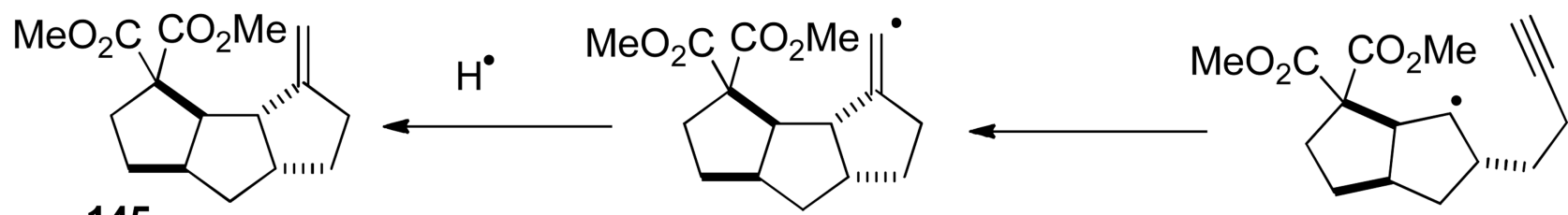

145

148

Figure 23.

Visible light-mediated radical cyclization of 144 and mechanism. 


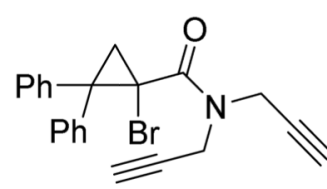

149

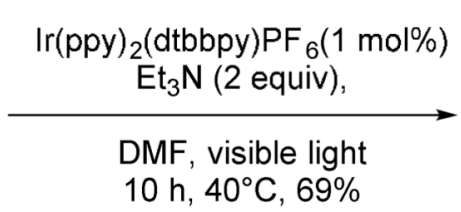

$10 \mathrm{~h}, 40^{\circ} \mathrm{C}, 69 \%$<smiles>C#CCN1CC2=C(CC(c3ccccc3)c3ccccc3C2)C1=O</smiles>

150

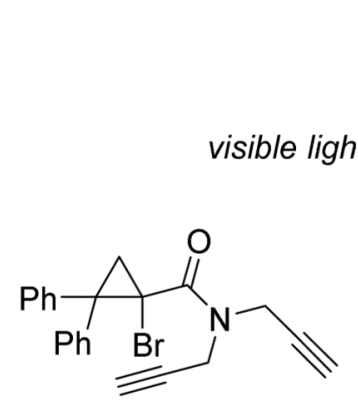

149

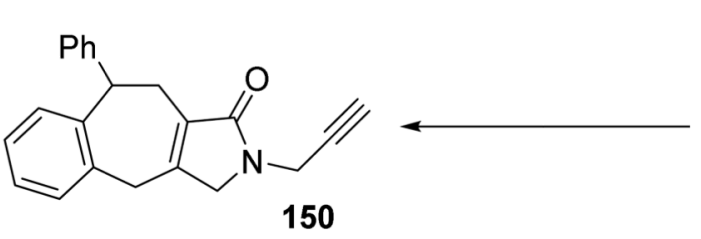<smiles>C#CCN1CC2=Cc3ccccc3C(c3ccccc3)CC3=CC(C)CCC3=CC2C1=O</smiles>

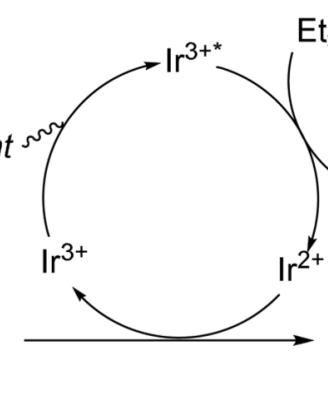

$\mathrm{Et}_{3} \mathrm{~N}:$<smiles>CCC[15NH2+]</smiles>

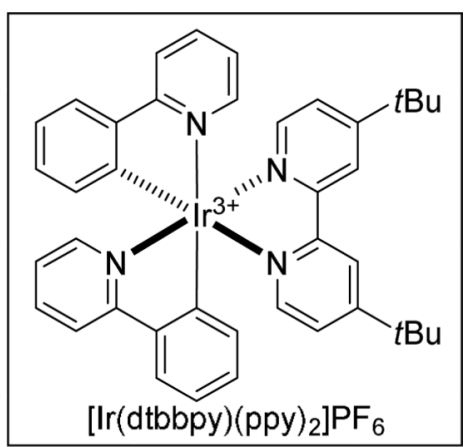

$\left[\mathrm{Ir}(\mathrm{dtbbpy})(\mathrm{ppy})_{2}\right]_{\mathrm{PF}}$
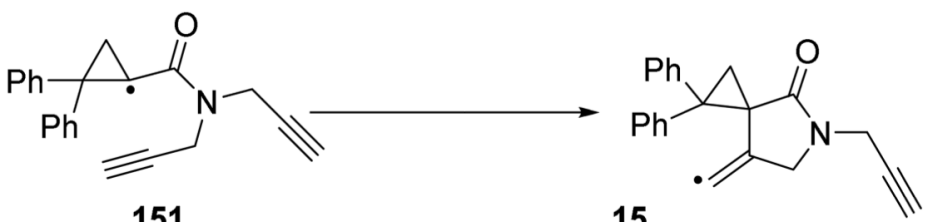

151

15

2

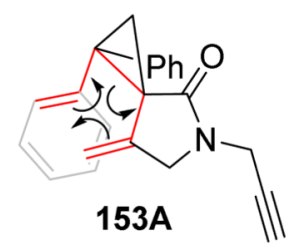

path A

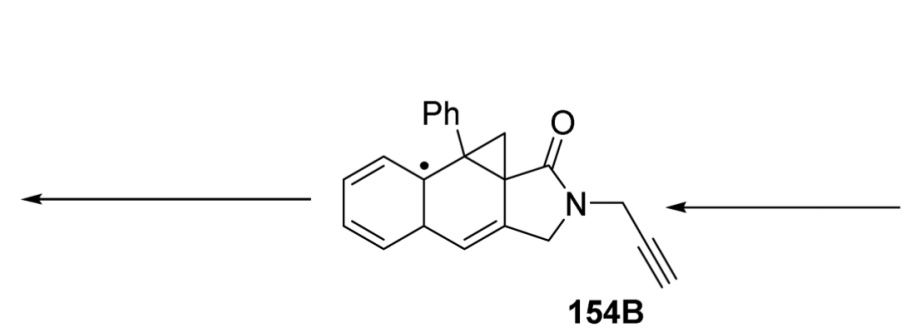

path B

Figure 24.

Visible light-mediated radical cyclization/fragmentation of $\mathbf{1 4 9}$ and mechanism. 

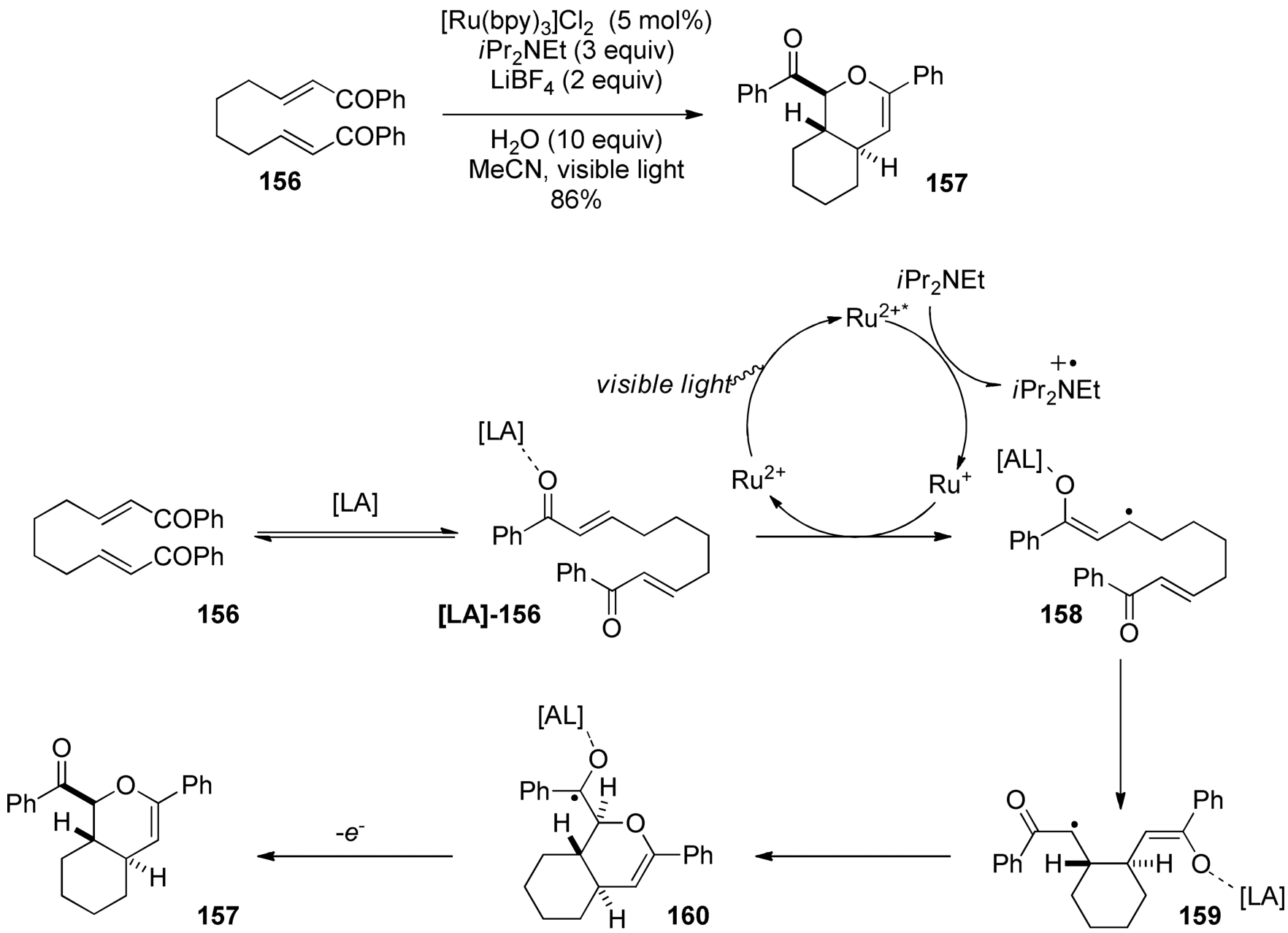

Figure 25.

Visible light-mediated redox neutral bicyclization of $\mathbf{1 5 6}$ and mechanism. 
<smiles>CCOC(=O)/C(C)=C/CCCC1CC1C(=O)c1ccccc1</smiles>

161
$\left[\mathrm{Ru}(\mathrm{bpy})_{3}\right] \mathrm{Cl}_{2}(2.5 \mathrm{~mol} \%)$ $\mathrm{La}(\mathrm{OTf})_{3}$ (1 equiv) TMEDA (5 equiv) $\mathrm{MgSO}_{4}, \mathrm{MeCN}$ visible light $83 \%, 6: 1 \mathrm{dr}$<smiles>CCOC(=O)[C@@]1(C)[C@H]2CCC[C@H]2C[C@H]1C(=O)c1ccccc1</smiles>

162<smiles>CCOC(=O)C(C)=CCCCC1(C(=O)c2ccccc2)CC1C(=O)[Al]CC</smiles>

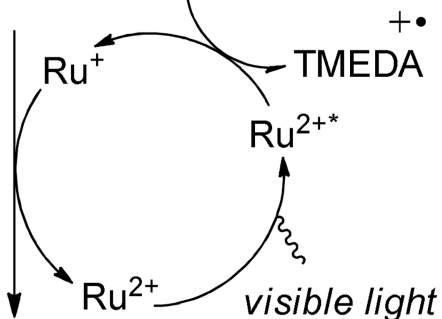

[LA]<smiles>CCOC(=O)/C(C)=C/CCCC1([13CH3])CC1C(O[AlH2])[PH2]c1ccccc1</smiles><smiles>CCOC(=O)[C@]1(C)[C@@H](C(=O)c2ccccc2)C[C@H]2CCC[C@]21C</smiles>

[LA]

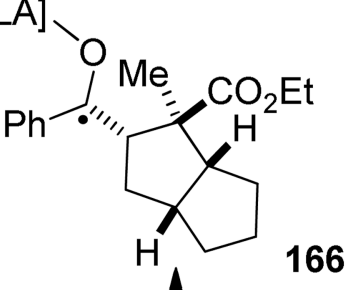<smiles>[AlH][AlH]</smiles><smiles>CCCCC=C(OC)c1ccccc1</smiles><smiles>CC=C(C)C(=O)OCC</smiles>

Figure 26.

Visible light-mediated redox neutral fragmentation/bicyclization of $\mathbf{1 6 1}$ and mechanism. 


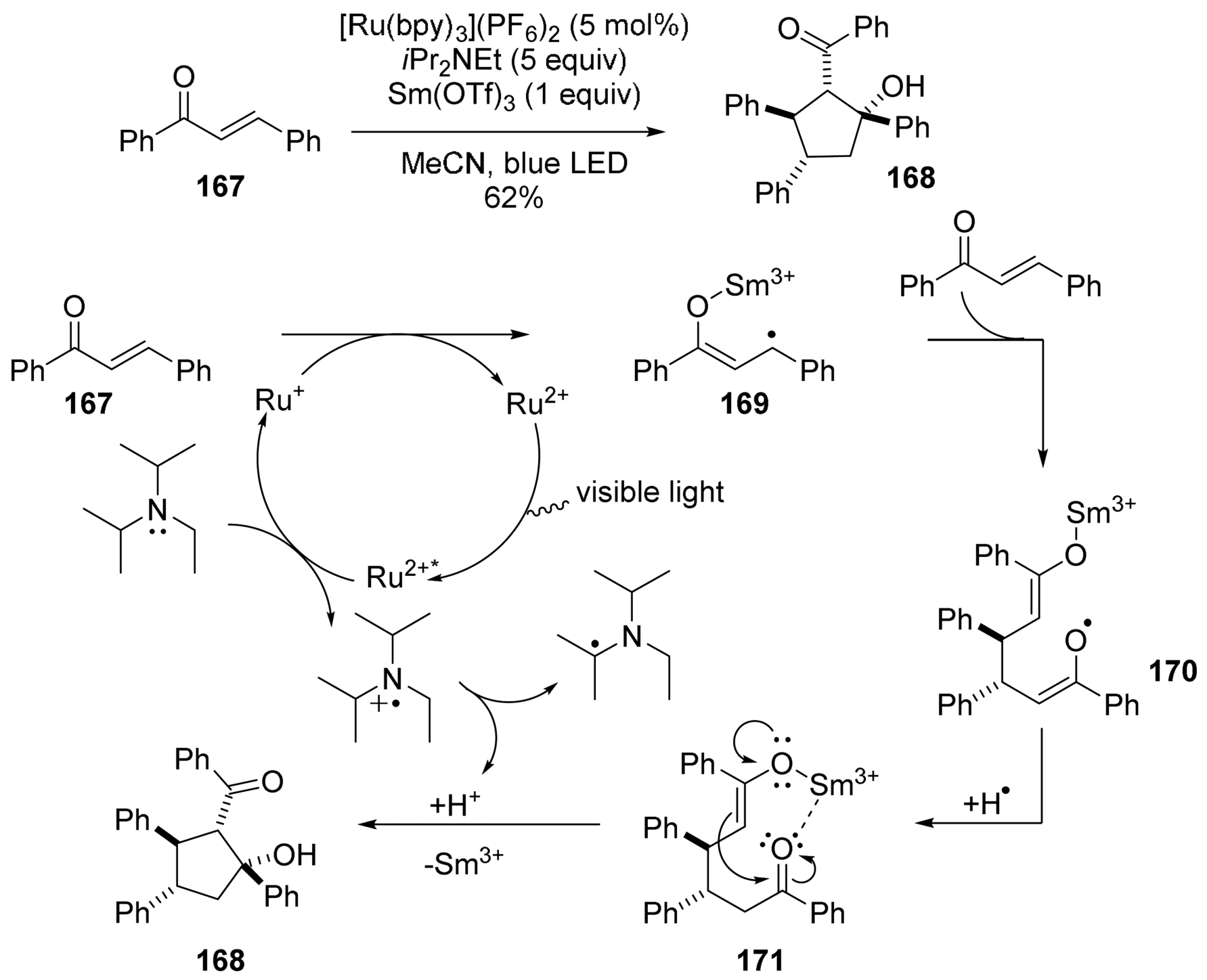

Figure 27.

Visible light-mediated redox neutral dimerization/cyclization of $\mathbf{1 6 7}$ and mechanism. 